\title{
An investigation of ducted and open-centre tidal turbines employing CFD-embedded BEM
}

\author{
C.S.K. Belloni, R.H.J. Willden*, G.T. Houlsby \\ Tidal Energy Research Group \\ Department of Engineering Science \\ University of Oxford \\ Parks Road, Oxford OX1 3PJ, UK
}

\begin{abstract}
This paper presents a numerical investigation of ducted tidal turbines, employing three-dimensional Reynolds-averaged Navier-Stokes simulations. Bidirectional ducted turbines are modelled with and without apertures, referred to as ducted and open-centre turbines respectively.

The turbine rotors are represented through a CFD-integrated blade element momentum model, employing realistic rotor data, capturing swirl and blade drag in addition to the extraction of linear momentum. The performances of bare, ducted, and open-centre turbines are investigated for axial flow, relating these to the flow fields exhibited. Substantial decreases in power generated by the ducted and open-centre turbines were found, relative to a bare turbine of equal total device diameter.

Two further measures of performance were employed: power density, normalising the power by the rotor area, and basin efficiency, relating the power generated to the overall power removed from the flow. Moderate increases in power density can be achieved for the ducted and open-centre devices, while their basin efficiencies are of similar value to that of the bare turbine.
\end{abstract}

Keywords: ducted tidal turbine, open-centre turbine, turbine efficiency, CFD-embedded BEM

\section{Introduction}

The use of diffusers or ducts for enhancing the performance of wind and tidal turbines has been in discussion for a many years (Foreman et al., 1978, van Bussel, 2007). In general two types of ducts have been proposed for wind 4 and tidal turbines: unidirectional ducts (diffusers) and bidirectional ducts. The former often consist of an aerofoil5 shaped cross-section that induces a circulation, and thus a lifting force toward the duct axis. The bidirectional duct is 6 designed to provide an increase of the flow velocity at the throat of the duct where the rotor is placed. Figure 1 shows

\footnotetext{
${ }^{*}$ Corresponding author

Email address: richard.willden@eng.ox.ac.uk (R.H.J. Willden)
} 

an example of each of these duct types. Little is known about the performance of such bidirectional ducts, and several commercial ventures using such a design have been pursued, and some abandoned in recent years.
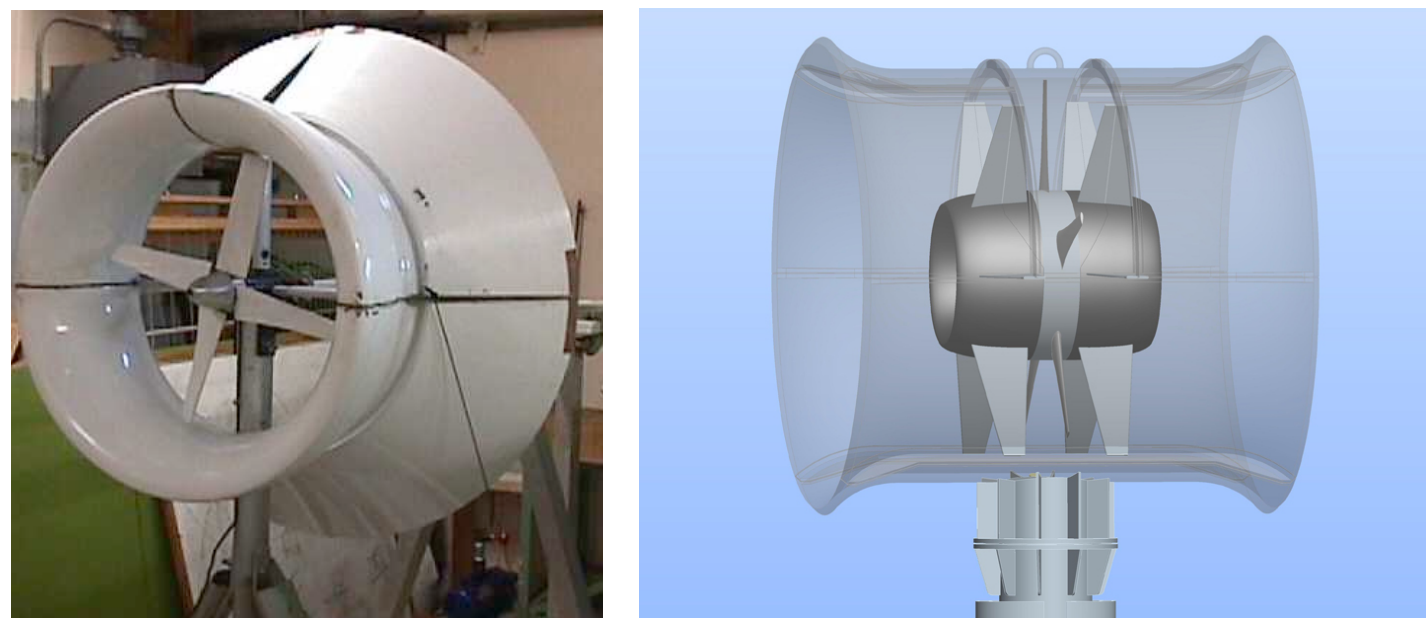

Figure 1: Examples of uni- and bidirectional ducts. Left: Vortec unidirectional duct for wind energy application (Phillips et al. 2005). Right: CleanCurrent bidirectional duct for tidal energy application (Clean Current Power Systems Inc. |2013).

The open-centre design approach also makes use of a bidirectional duct, adding an aperture at the turbine centre. In the case of the open-centre turbine the duct is essential component for housing the generator parts, rather than designed for a flow acceleration. The central opening of this design is said by its proponents to produce a jet and thus a low pressure region, providing a suction effect to accelerate the flow through the turbine, increasing the power take off.

Whilst the concept of encasing turbine blades in a shroud has not proven viable for large wind turbines, a wide range of ducted tidal devices have been suggested. The manufacturers of these devices claim a substantial increase in power in comparison to bare devices as well as other advantages such as better performance in yawed flow conditions and lower maintenance costs (Thorpe, 2005).

Independent analyses of unidirectional ducted turbines using primarily Computational Fluid Dynamics (CFD) generally indicate a substantial increase in power compared to that of a bare turbine (Hansen et al., 2000, Gaden and Bibeau, 2010) when based on the same rotor diameter. However, the choice of reference area (i.e. rotor area or diffuser exit/entry area) has a significant impact on the presented efficiencies, something that was not taken into account in the studies mentioned above and has been addressed in detail in Belloni (2013).

Setoguchi et al. (2004) studied flows through empty bidirectional ducts of various external shapes, but common internal shape. The best results are obtained with a cylindrical outer shape of the duct, for which flow velocities at the throat increase up to 1.3 times the free-stream. In general a significant effect of the outside shape of the duct on the flow within the duct is reported. While studying an interesting topic of external duct shapes, this study did not take into consideration the influence of the rotor within the duct on the flow field. 

as

Unidirectional ducts are not constrained by symmetry for and aft of the rotor plane, and hence can be designed to efficiently expand the downstream flow. Thus the flow of a bidirectional duct differs considerably from that of a unidirectional duct, and therefore limited conclusions can be drawn for the tidal problem from unidirectional duct studies. Further, analysing the duct without a turbine disregards the influence of the turbine resistance on the flow, and the resulting flow interaction with the duct flow field. Analyses modelling both the duct and turbine are required to properly understand this interaction, as addressed in this study.

Blade element momentum (BEM) methods embedded in Reynolds-averaged Navier-Stokes computational fluid dynamics (CFD) solvers, here referred to as RANS-BEM models, provide a powerful and efficient tool for designing and studying tidal turbines. While capturing real rotor effects such a swirl and momentum extraction, discrete blades are not modelled, thereby reducing significantly the meshing and computational effort compared to fully blade-resolved CFD models.

In this computational study a RANS-BEM model is employed to analyse and compare the performance of bare, ducted, and open-centre tidal turbines, employing realistic rotor data. A realistic hydrofoil is selected and a rotor optimisation tool is employed to determine hydrodynamically optimal rotor designs for each of the devices. The devices are then simulated, employing the generated rotor designs, and compared based on key performance parameters.

\section{Definitions}

When adressing studies of ducted turbines, it is crucial to understand the precise boundary conditions employed and the measures used for analysing performance. As discussed in Belloni et al. (2013), the blockage ratio, $B$, of an experimental or numerical domain has a substantial impact on the performance of a tidal device. It is defined

$$
B=\frac{\text { device blocked area }}{\text { channel cross-sectional area }}=\frac{A_{\text {device }}}{A_{\text {domain }}}
$$

where $A$ is the cross-sectional area. While for a bare turbine $A_{\text {device }}=A_{\text {rotor }}$, for a ducted turbine $A_{\text {device }}>A_{\text {rotor }}$.

The conventional method of quantifying the "efficiency" of a turbine is given by the nondimensional power coefficient,

$$
\begin{aligned}
C_{P} & =\frac{\text { turbine power }}{\text { undisturbed power flux }} \\
& =\frac{P}{1 / 2 \rho A_{\text {ref }} U_{\infty}^{3}}
\end{aligned}
$$

where $P$ is the power generated by the turbine, $A_{\text {ref }}$ the reference area, and $U_{\infty}$ the free-stream flow velocity. For instance, the well known Lanchester-Betz limit for low blockage flow yields the optimal value of $C_{P}=16 / 27$. It is conventional to take the rotor frontal area as the reference area when studying bare rotors, however there are several 
choices of area when considering ducted rotors. An early study into ducted wind turbines by Lilley and Rainbird (1956) analyses the performance of the ducted turbine based on the total device frontal area, therefore employing $A_{\text {device }}$ as $A_{\text {ref. }}$. However, nearly all other authors investigating the performance augmentation by ducts, choose the rotor area $A_{\text {rotor }}$ as the reference area. It is clear that as $A_{\text {device }}>A_{\text {rotor }}$, normalising power on $A_{\text {rotor }}$ leads to the reporting of much higher power coefficients.

A further important non-dimensional parameter in the field of turbine hydrodynamics is the thrust coefficient $C_{T}$, which quantifies the streamwise force on the turbine disc. $C_{T}$ is defined as

$$
\begin{aligned}
C_{T} & =\frac{\text { force acting on turbine }}{\text { kinetic pressure force upstream }} \\
& =\frac{T}{1 / 2 \rho A_{\text {ref }} U_{\infty}^{2}}
\end{aligned}
$$

It is useful further to define a local thrust coefficient,

$$
C_{T, \text { loc }}=\frac{T}{1 / 2 \rho A_{\text {ref }} U_{\mathrm{t}}^{2}}
$$

which normalises the thrust by the velocity at the disc, $U_{\mathrm{t}}$, (rather than the free-stream velocity, $U_{\infty}$ ). It is this factor that is used in numerical models in order to specify the disc thrust level.

\section{Methods}

Numerical modelling allows high resolution flow field data representing full scale. Such data can be analysed to gain insight into the fluid mechanics of ducted tidal turbines. This section gives a short overview of two popular computational turbine models used in tidal turbine research, the model employed in this study, RANS-BEM, and for comparison the actuator disc model, a simpler approach.

\subsection{RANS solver and turbulence modelling}

The software employed to perform the present simulations is ANSYS FLUENT 12.0, which is used to solve the governing flow equations: continuity and the incompressible three-dimensional Navier-Stokes equations. We are concerned with simulating realistic device scales and so all flow scales cannot be resolved. We choose to employ the Reynolds Averaged Navier-Stokes equations with a two equation turbulence closure model; the k- $\omega$ SST turbulence model.

The k- $\omega$ SST turbulence model was chosen for its ability to model separated flows (Menter, 1993), as have been reported to occur for ducted devices (Gaden and Bibeau, 2010; Fleming and Willden, 2016). Aplsey and Leschzinger 
(1999) investigate the ability of various two equation turbulence models to predict separated flow in a diffuser by comparing them to experimental data. The results suggest that the k- $\omega$ SST turbulence model outperforms all other two-equation models analysed in their study.

\subsection{Actuator disc modelling}

A popular approach to modelling turbines is to represent the turbine as an actuator disc, implemented using a numerical porous disc. This method assumes steady flow, neglects effects caused by discrete blades and swirl, and solely models the reduction of linear momentum through the turbine rotor. The actuator disc approach is independent of the rotor design, as the turbine is modelled as an ideal energy extractor. Embedded in a numerical solver, it is a widely used tool for modelling wind turbines (Sørensen and Myken, 1992, Mikkelsen, 2003) and tidal turbines (MacLeod et al. 2002; Batten et al. 2013).

A study of ducted turbines with and without apertures using actuator discs is presented in Belloni and Willden (2011) and Belloni et al. (2013). The results of this previous analysis of bare, ducted, and open-centre turbines will be compared to the analysis presented here.

\subsection{RANS-BEM modelling}

An effective method for numerical modelling of turbines is to employ a CFD-embedded blade element momentum (BEM) model (Turnock et al., 2011; Masters et al., 2013, Schluntz and Willden, 2015). In BEM theory the rotor is modelled by applying force data to the flow based on actual rotor characteristics. Using tabulated blade coefficient data, both linear momentum extraction as well as angular momentum effects can be captured. The blades are not modelled discretely, but are divided into radial blade sections. The blade forces at a given radial location are evenly distributed circumferentially over a rotor revolution, resulting in a set of concentric annuli acting essentially as separate actuator rings. Due to the smearing of the blade forces around a revolution, discrete blade effects (such as tip vortices) are not captured in this approach. The benefits of this approach are that, as for the actuator disc method, the blades need not be modelled and a steady flow solution is obtained, leading to a computationally efficient solution (though it is noted that unsteady simulations may be required to capture certain unsteady flow effects generated by the support ducts and support structure). At the same time, real rotor data may be applied, yielding more realistic flow field and performance data compared to the actuator disc method.

The present study employs an in-house RANS-BEM code and design tool embedded in ANSYS FLUENT, which has been verified and used in the design of bare and ducted turbines (McIntosh et al., 2011; Fleming and Willden, 2016). Schluntz (2014) and Belloni et al. (2013) found good agreement when comparing RANS-BEM results with actuator line simulations, and analytical BEM, respectively. 
Figure 2 illustrates the velocity and angle terminology used in the discussion of the blade element. The circumferential

The RANS-BEM model applies the BEM method as a boundary condition within FLUENT (ANSYS Inc., 2009), with the rotor represented as a thin disc, as in actuator disc simulations. The axial blade forces acting on the flow are reproduced by applying a jump in static pressure $\Delta p$ across the disc,

$$
\Delta p=\frac{1}{2} \rho U_{\mathrm{rel}}^{2} \sigma_{r}\left(C_{l} \cos \phi+C_{d} \sin \phi\right)
$$

where $C_{l}$ and $C_{d}$ are the dimensionless sectional lift and drag coeffcients, and $U_{\text {rel }}$ is the relative blade inflow velocity. The local blade solidity $\sigma_{r}$ is defined as

$$
\sigma_{r}(r)=\frac{N_{B} c(r)}{2 r \pi}
$$

with $N_{B}$ the number of blades, $c(r)$ the chord length at radial station $r$.
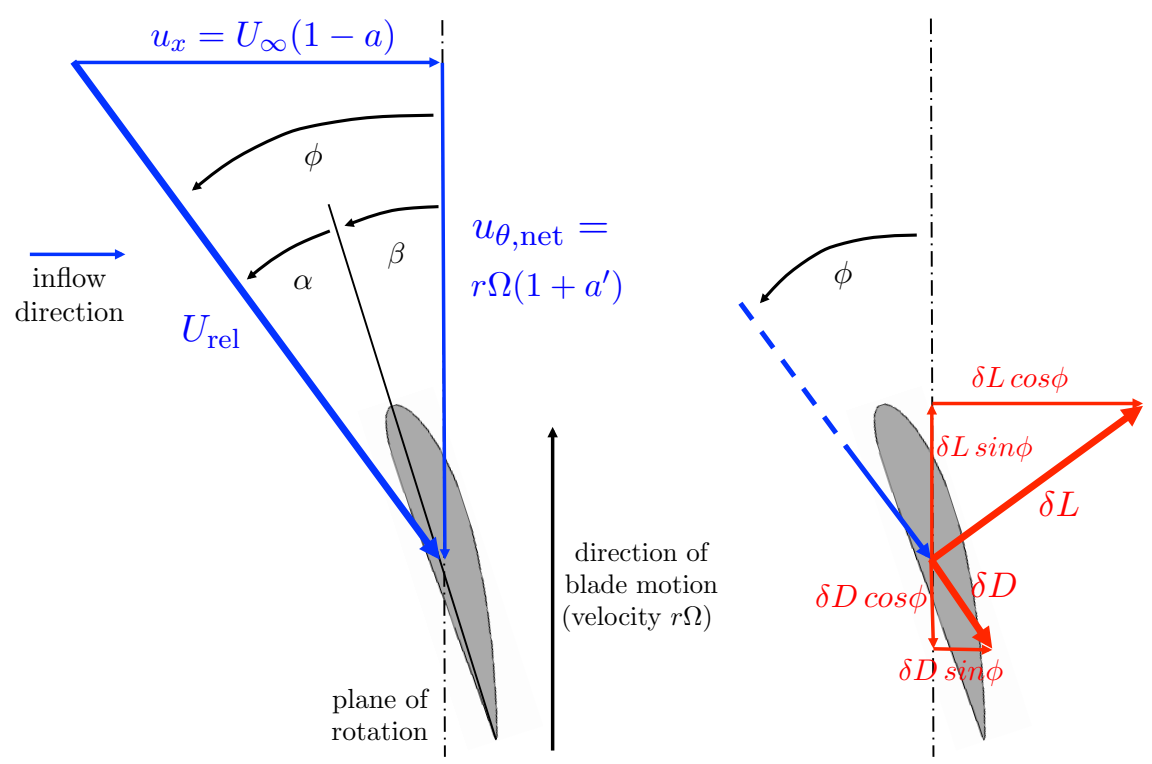

Figure 2: Illustration of velocities and forces acting on a blade section. 
the turbine plane, $u_{\theta, t}$,

$$
u_{\theta, \text { net }}=r \Omega-u_{\theta, t} .
$$

The incident blade velocity, $U_{\text {rel }}$, is defined as the resultant of the streamwise, $u_{x}$, and the net circumferential, $u_{\theta \text {, net }}$, velocity components,

$$
U_{\text {rel }}=\sqrt{u_{\theta, \text { net }}^{2}+u_{x}^{2}} \text {. }
$$

The Prandtl tip-loss model is implemented in the RANS-BEM code and may be enabled when required. The tip correction factor,

$$
F=\frac{2}{\pi} \cos ^{-1}\left[\exp \left(\frac{N_{B}\left(1-\frac{R}{r}\right)}{2 \sin \phi}\right)\right]
$$

is applied in the current model as a multiplication factor to the local induction factor. The effect of the tip correction factor is to decrease the local induction factor and hence increase the axial velocity near the blade tips, in order to account for flow entrainment at the blade tips. This increase in axial velocity leads to an increase in angle of attack in this region. Depending on the rotor geometry and the operating point of the rotor, this increase in $\alpha$ can lead to either an increase or decrease in power compared to a turbine where tip vortex effects have been neglected. Note that the tip correction factor is often applied incorrectly, as discussed in detail by Schluntz (2014). A typical error is the application of the factor to the velocity rather than the axial induction factor, thereby leading to a loss in axial flow velocity rather than an increase. For the ducted rotor the increase in axial velocity near the blade tips is small, suggesting that the application of the tip-loss model is not appropriate for these simulations, as further shown in a numerical study by Fleming and Willden (2016). Therefore in the present study the tip-loss factor is set equal to unity for all ducted rotor simulations.

In the present model, in contrast to the standard approach used in CFD-embedded BEM models (see for instance Malki et al. (2013)), the rotor forces are not applied uniformly across an annulus, but instead are applied to each cell independently, according to the local flow conditions. This method can be best visualised as a large number of thin streamtubes of cell-sized cross-section (at the rotor plane), passing through the disc ("spaghetti" approach). This model can thus account for azimuthal variations in the rotor flow field, as are expected for cases of non-axial flow.

\subsection{Domain and solver setup}

The devices are considered in nearly unconstrained flow, representing in a row of turbines arrayed normally to the flow direction, a layout being pursued for farms of turbines. The domain extends 8.1 diameters, D, (130 m) upstream of the $16 \mathrm{~m}$ diameter disc, $260 \mathrm{~m}$ (16.2D) downstream and $75 \mathrm{~m}$ (4.7D) in the cross-stream direction, resulting in a blockage ratio of $B=0.035$. Figure 3 illustrates the simulation domain. 


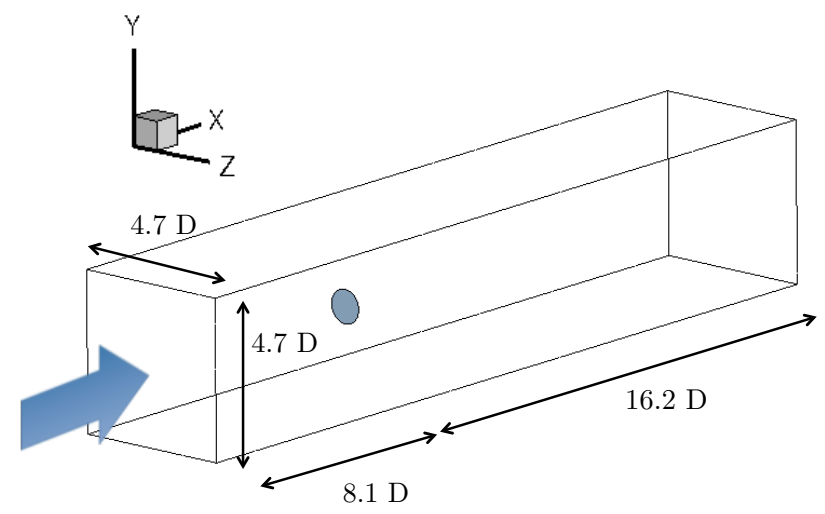

Figure 3: The simulation domain.

The following boundary conditions were employed: uniform inlet velocity $\left(U_{\infty}=2 \mathrm{~m} / \mathrm{s}\right)$, uniform outlet pressure $(p=0 \mathrm{~Pa})$ and flow symmetry on the remaining boundaries. The resulting Reynolds number defined on the turbine diameter is $\operatorname{Re}=O\left(10^{7}\right)$, and the blade Reynolds number based on local chord and inflow velocity relative to the blade is $\operatorname{Re}=O\left(10^{6}\right)$.

The cell count is approximately $2 \times 10^{6}$ for the bare turbine and $5 \times 10^{6}$ for the ducted and open-centre turbines. The $y+$ range on the hub and duct walls is $15-200$ depending on axial position and flow condition. The mesh structure consists of flat layer prism cells growing from duct and hub walls developing into an unstructured mesh throughout the domain. Resolution is concentrated in regions of high shear including the trailing edge of the duct and across the wake of the device. Meshes were tested with convergence assessed relative to integral load quantities as well as wake centreline velocity development.

\section{Model setup and rotor design}

As discussed above, when employing RANS-BEM simulations, a rotor design must be chosen. As the goal is a fair comparison of different tidal turbine devices, it is of importance to tailor the rotor design to each environment. A rotor designed for a bare turbine will not yield the best results in ducted operation, see McIntosh et al. (2011). Similarly, a rotor designed for low blockage flow will operate sub-optimally in high flow blockage, see Schluntz and Willden (2015). This section introduces the rotor design criteria and tool used to design three turbine rotors: bare, ducted and open-centre turbines. The rotor designs are then employed in subsequent investigations.

\subsection{Hydrofoil selection}

The hydrofoil selection forms a central part of the design process, as the lift to drag characteristics of the chosen hydrofoil limit the maximum performance of the rotor. Much of the foil development of the past century has been 
focussed on aerospace and wind turbine applications, hence the foils are usually referred to as aerofoils and will be referred to as such in this study. Choice of an aerofoil determines the optimal angle of attack, which is found at the maximum ratio of lift to drag, $\left(C_{l} / C_{d}\right)_{\max }$.

Due to the structural requirements for tidal current turbines generally, aerofoils with a thickness to chord ratio of $t / c>20 \%$ are usually employed (Evans et al.,2013). A range of suitable choices of aerofoils for hydrokinetic turbine applications are discussed in Ahmed (2012), and the aerofoil selected for the present study is the Risø-A1-24. The data available for the Risø-A1-24 aerofoil covers a broad range of incidence angles (Fuglsang et al., 1999). In Ahmed (2012) this aerofoil is suggested as a popular choice within the tidal turbine industry, a claim further supported by Sale et al. (2009) where tidal turbine blade design is conducted using the Risø-A1 aerofoil family. For the Ris $\varnothing$-A1-24 the maximum ratio of lift over drag, $\left(C_{l} / C_{d}\right)_{\max }=58$, is found at $\alpha_{\text {target }}=7^{\circ}$, see figure 4

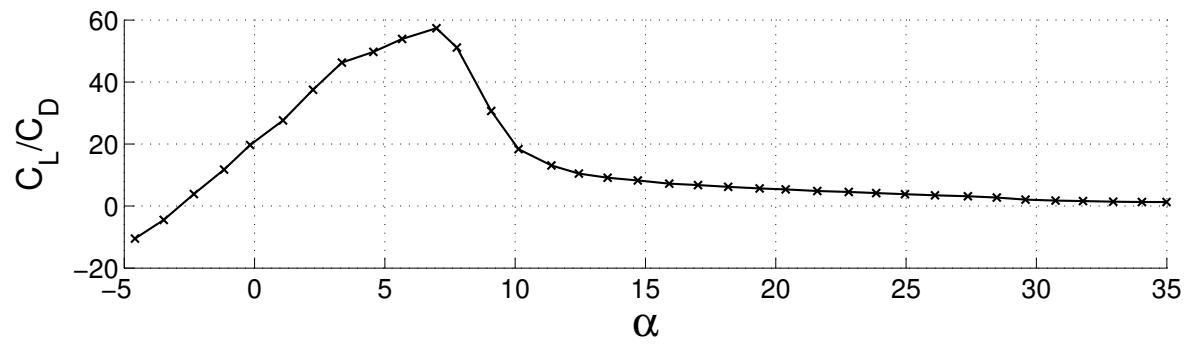

Figure 4: Ris $\varnothing$-A1-24 ratio of lift to drag coefficient for aerofoil investigated with leading edge roughness. Data reproduced from Fuglsang et al. (1999).

\subsection{Rotor design approach}

A rotor design is given by foil geometry together with the blade twist, $\beta$, and the local blade solidity, $\sigma_{r}$, for each radial station. Once the number of rotor blades, $N_{B}$, is chosen, the chord lengths, $c(r)$, can be derived using equation (6).

The blade twist is the principal variable that determines the local angle of attack, $\alpha$, while the solidity mainly controls the local thrust, $C_{T, \text { loc }}$, that the blade section exerts on the flow. In the design process it is thus necessary to set a design angle of attack and a design local thrust in order to define the rotor geometry.

However, the optimal design local thrust is not straightforward to determine. From linear momentum actuator disc theory the optimal local thrust coefficient for a bare turbine in unblocked flow is known $\left(C_{T, \text { loc }}=2\right.$, see for instance Belloni et al. (2013)). For blocked flow, however, higher $C_{T, \text { loc }}$ values give optimal performance and the value must be found iteratively. Further, as the velocity of the flow varies radially it is not clear that a radially constant $C_{T, \text { loc }}$ would lead to maximum power. This question has been investigated in Belloni (2013) and Hunter et al. (2015) confirming that a constant $C_{T, \text { loc }}$ is appropriate for design purposes. 


\subsection{RANS-BEM rotor design tool}

A rotor design tool is included in the RANS-BEM code employed for this study, McIntosh et al. (2011). Given two target design values ( $\alpha_{\text {target }}$ set to be the angle of attack at maximum lift to drag ratio and $C_{T, \text { loc }}$ ) the tool adjusts the blade parameters $\beta$ and $\sigma_{r}$ until the target values are met at each solution point along the blade. This design adjustment is performed at each RANS iteration step. As the steady simulation converges towards a solution, so does the rotor design in parallel, thus avoiding the need for additional design iterations. The solution was deemed converged when the target values were met within a tolerance of $1 \%$. The rotor design follows the scheme illustrated in figure 5

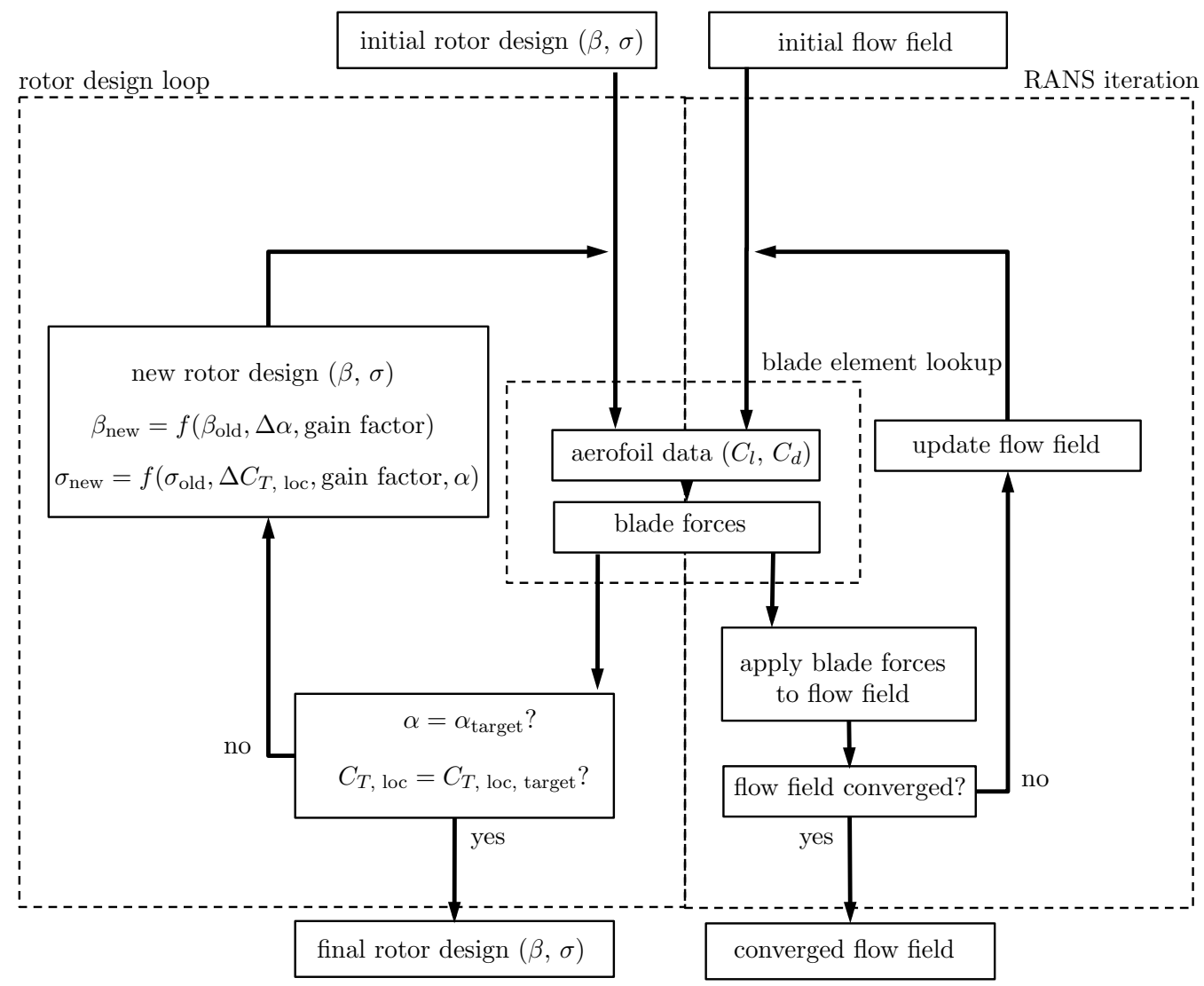

Figure 5: Flow chart of the RANS-BEM rotor design procedure.

The input values required for the design iteration are the aerofoil data (immediately resulting in the target angle of attack, $\alpha_{\text {target }}$ ), initial rotor geometry and a target value for local thrust, $C_{T, \text { loc }}$. After each RANS iteration the current values of $\alpha$ and $C_{T, \text { loc }}$ are compared to the respective target values. The difference between target values and actual values is computed and multiplied by a gain factor (e.g. 0.05) which may be adjusted manually. The resulting incremental change is then applied to the design until the solution converges and the target values are met.

There are certain physical limitations which result in the target values not being reached. One such limitation is 
the solidity limit applied to the rotor, which has been set to $\sigma_{\text {imit }}=0.95$. This limit prevents the design tool from generating unrealistic rotor designs close to the hub.

The design routine is performed multiple times for a range of values of $C_{T, \text { loc, target }}$ and tip speed ratio, $\lambda$, resulting in a matrix of rotor designs. For each combination of $C_{T, \text { loc, target }}$ and $\lambda$ the device performance is obtained. The performances of all design combination are compared and the design with maximum performance is chosen for the device rotor. The rotor design process uses the power coefficient as defined in equation (2) as the criterion to be maximised. Thus the rotors are designed for maximum power for a given device frontal area.

\subsection{Result of the rotor design process}

Dimensions of the bare turbine including both disc and hub were chosen after a review of current designs used in industry, and are presented in figure $6 \mathrm{a}$ The ratio of hub radius to tip radius is $R_{\text {hub }} / R_{\text {tip }}=1.2 \mathrm{~m} / 8 \mathrm{~m}=15 \%$, and the disc is located at $22 \%$ of the nacelle length from the nose. The ends of the hub are modelled as cones with rounded tips. Figure $6 \mathrm{~b}$ illustrates the ducted device dimensions. The geometry of the duct corresponds to that used in Belloni et al. (2013), apart from the inclusion of the hub. The hub is placed symmetrically within the disc and duct and follows a typical design proposed by the industry (van Drentham Susman et al., 2011). The geometry of the open-centre turbine is as in Belloni (2013) except for the inclusion of a hub. The hub of the open-centre turbine is in the shape of an axially extruded ring with rounded leading and trailing edges, see figure $6 \mathrm{c}$. Due to the nature of this design, the assumption is that the generator is housed within the outer duct and that the rotor blades are attached to a rotating ring section within that duct. A single aperture size is investigated, $R_{\mathrm{ap}}=1.65 \mathrm{~m}$.

The three rotor designs for which maximum power is achieved have been selected. The rotor designs obtained through the RANS-BEM design tool exhibit minor anomalies near the root and the tips, see figure 7 These anomalies stem from the design process which adjusts the rotor design during each iteration. In areas of highly sheared flow, near the tips and the hub, the iteration does not fully converge on a design solution, creating these anomalies in the design. As these anomalies arose from the numerical methods, data smoothing was applied. Following data smoothing using a moving average function, the designs for the rotors are plotted in figure 7 . Note that the radial position is plotted as a function of tip radius, $R$. Due to the differences in tip radius between bare and ducted turbine the relative position of the blade root changes, even though $R_{\text {hub }}$ is of equal size for both designs.

Significant differences in the optimal rotor design are noticeable when comparing the three custom designs. As can be seen in figure 7, the twist of the ducted and open-centre rotors is similar, but significantly higher than for the bare rotor by $10^{\circ}-15^{\circ}$ along the full blade span. This offset in twist angle is due to the higher flow velocities through the turbine plane achieved by the ducted devices. Together with a lower $\lambda$ to achieve peak performance, the twist needs to be increased compared to the bare rotor so that the rotor blade operates close to the optimal angle of attack, $\alpha_{\text {target }}=7^{\circ}$. 

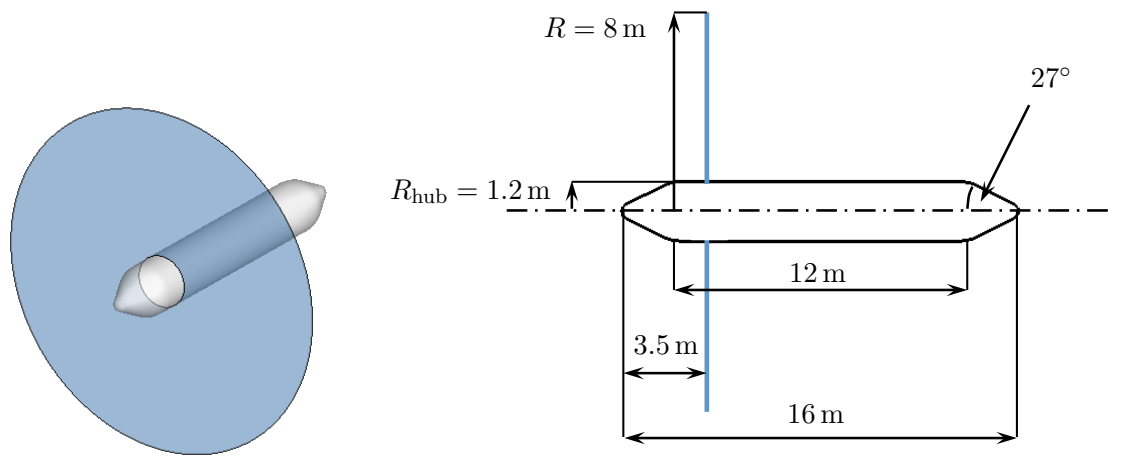

(a) Bare turbine
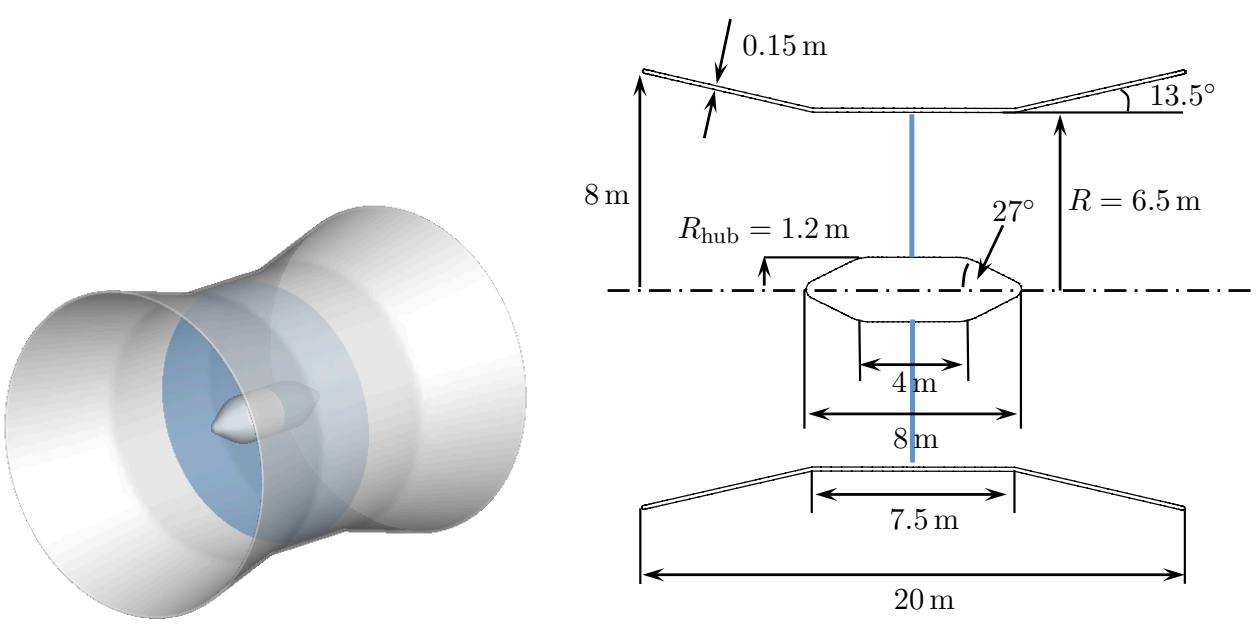

(b) Ducted turbine.
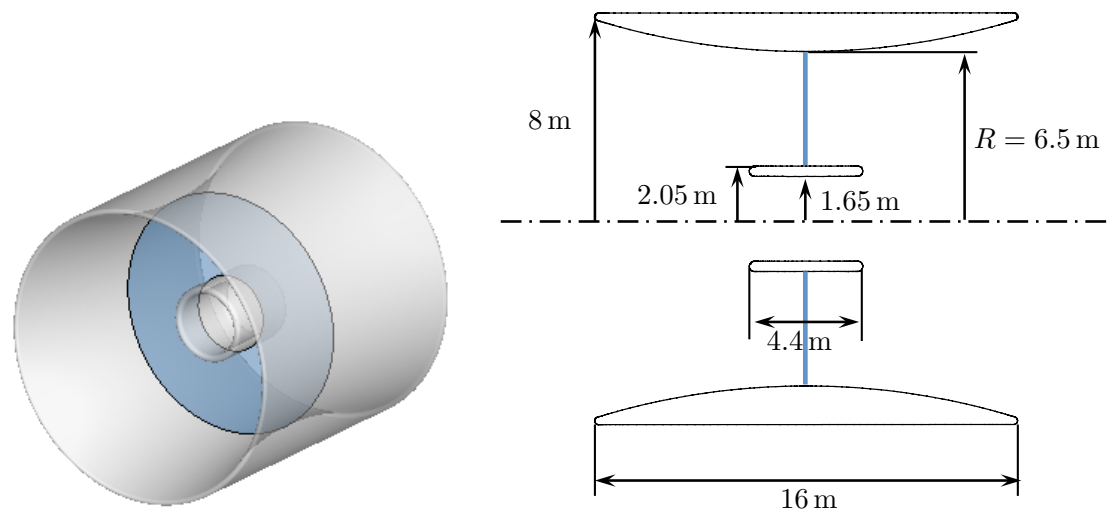

(c) Open-centre turbine.

Figure 6: Device design.

The results of blade solidity derive from the requirement to resist the flow by the given $C_{T, \text { loc, target }}$, which is dependent on both $\sigma_{r}$ and $\lambda$. The open-centre turbine is designed at a lower $\lambda$ but for a higher $C_{T, \text { loc, target }}$, compared to the ducted turbine. Therefore in order to achieve $C_{T, \text { loc, target }}, \sigma_{r}$ must increase significantly as compared to the ducted turbine, 

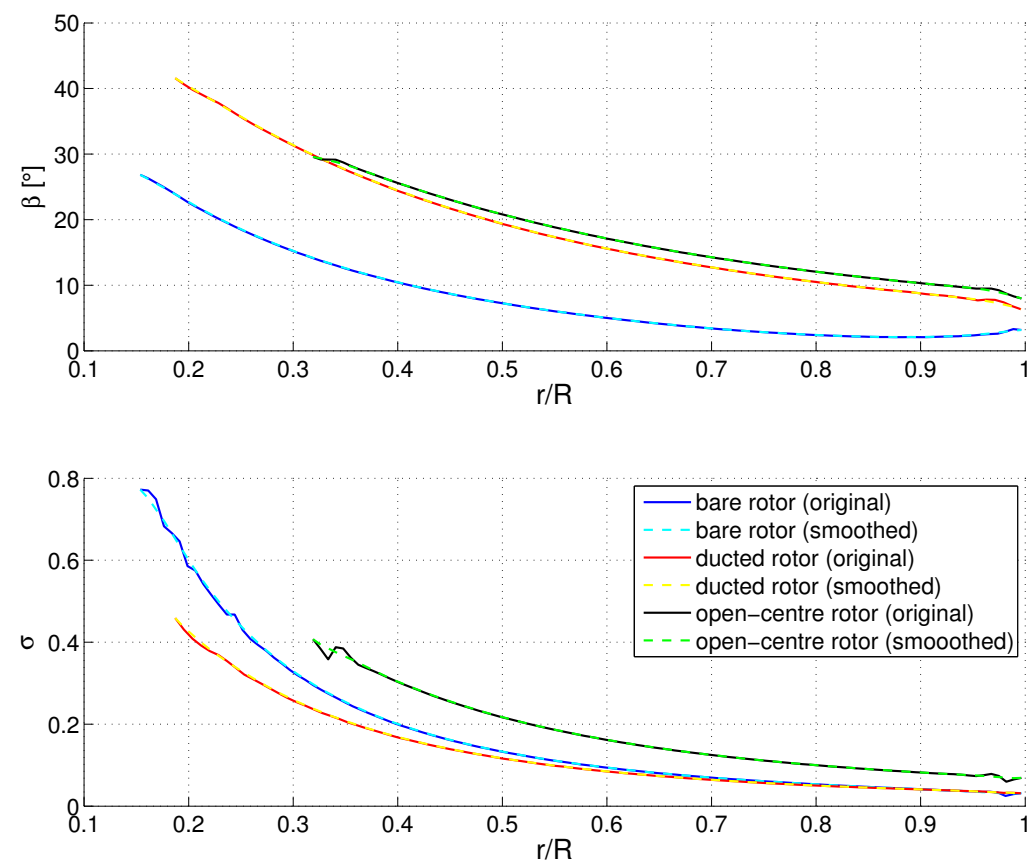

Figure 7: Result of the rotor design process for all three devices.

see figure 7

\section{Analysis of the bare turbine}

The analysis of the bare turbine configuration introduced in section 4 is presented first. The presentation follows that of Belloni et al. (2013), discussing first the flow field, then the thrust acting on the turbine and finally the performance of the turbine.

\subsection{Flow field for the bare turbine}

Fig 8 presents the streamlines and velocity contours in a horizontal cut-plane of the bare turbine simulations for various values of $\lambda$, including the design point at $\lambda=5$. As $\lambda$ is increased, the thrust acting on the fluid increases, and hence the approaching streamtube widens. The hub generates a wake within the rotor wake, while swirl is generated at the rotor plane and is clearly visible in the wake. Further, radial variation in velocity through the disc is observed.

As the flow is axisymmetric around the rotation axis, it is convenient to present the flow data at the rotor plane as a function of radial position, and thus more easily compare the data of design and off-design operation. Azimuthal 

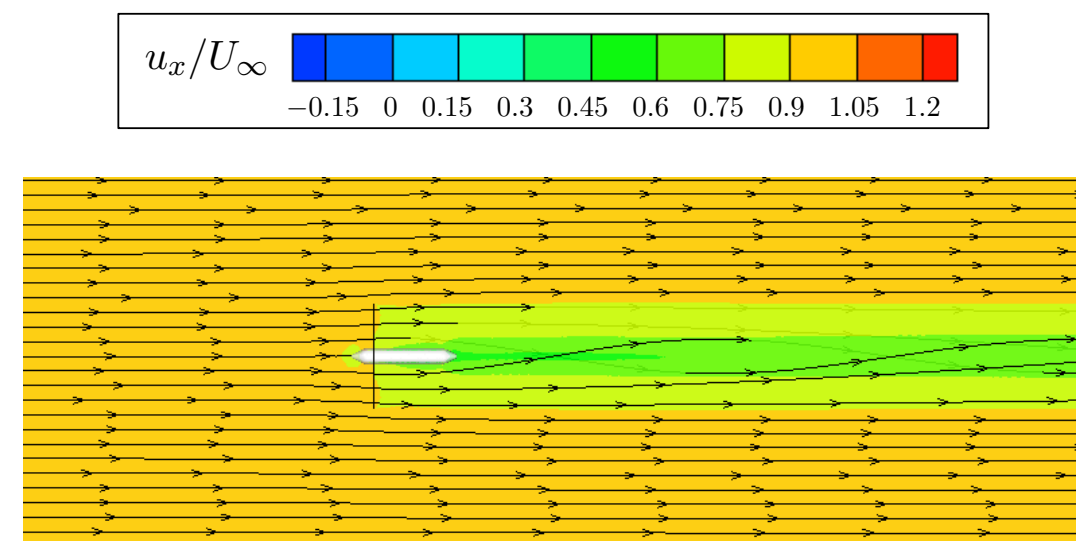

(a) $\lambda=3$

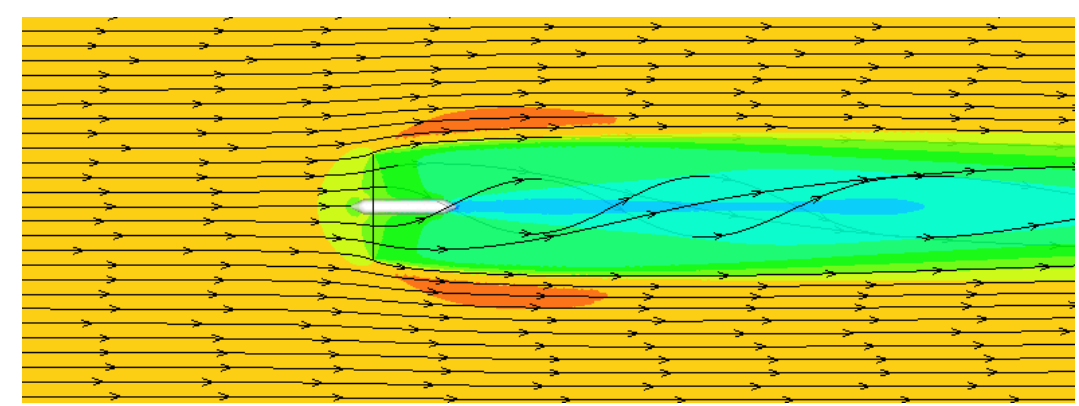

(b) $\lambda=5$, design point

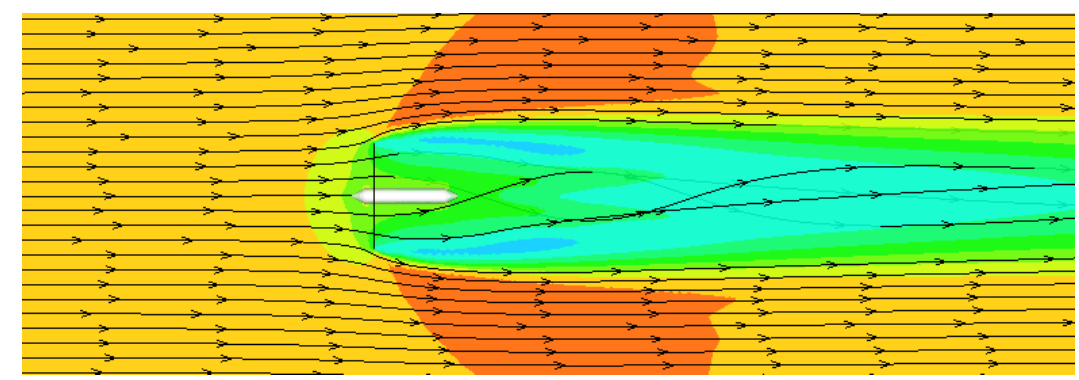

(c) $\lambda=7$

Figure 8: Flow field of the bare turbine shown in the horizontal cut-plane for various levels of $\lambda$. The rotor plane is shown by a straight vertical line.

averaging is applied to remove numerical scatter. The results for velocity, angle of attack and local thrust coefficient are presented in figure 9

At the design point, $\lambda=5$, the values of $\alpha$ and $C_{\mathrm{T}}$ loc are nearly constant across the span, achieving the design target, as is the axial velocity at the rotor. For low tip-speed ratio operation $(\lambda=3,4)$ the flow induction is reduced and $u_{x}$ therefore increased. The angle of attack increases at the hub, leading to stall on the aerofoil. $C_{\mathrm{T}, \text { loc }}$ is significantly reduced across the whole span. For high tip-speed ratio operation, a drop in axial velocity occurs towards the tip of the blade due to the increase in the radial velocity component. As the rotational velocity is increased $(\lambda=6,7)$, the 

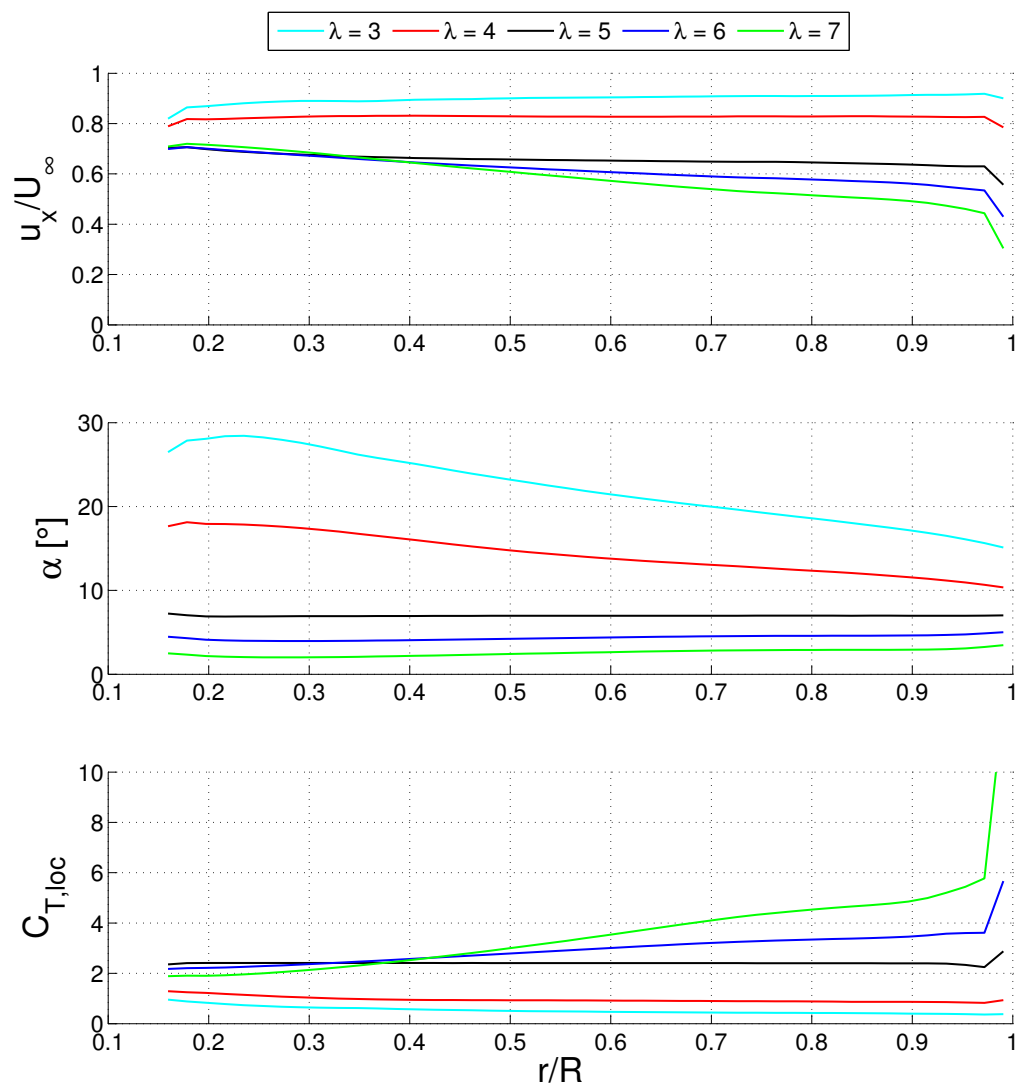

Figure 9: Azimuthally averaged flow results of the bare turbine for $3 \leq \lambda \leq 7$.

\subsection{Thrust on the bare turbine}

The thrust on the bare turbine is split into two components, the thrust on the hub and the thrust on the rotor. The force on the rotor results directly from the BEM calculation within the code while the force on the hub is obtained through integration of surface pressure and wall shear stress. Figure 10 presents the results of this thrust analysis. Both the thrust on the rotor and the hub are normalised using $1 / 2 \rho U_{\infty}^{2} A_{\text {device }}$ in order to present the quantitative difference in thrust posed by the elements of the device.

It can be seen from figure 10 that for the aligned flow, the thrust on the hub is very small compared to that on the rotor. However, although small compared to the rotor thrust, the thrust of the hub more than doubles over the range of $\lambda$ 


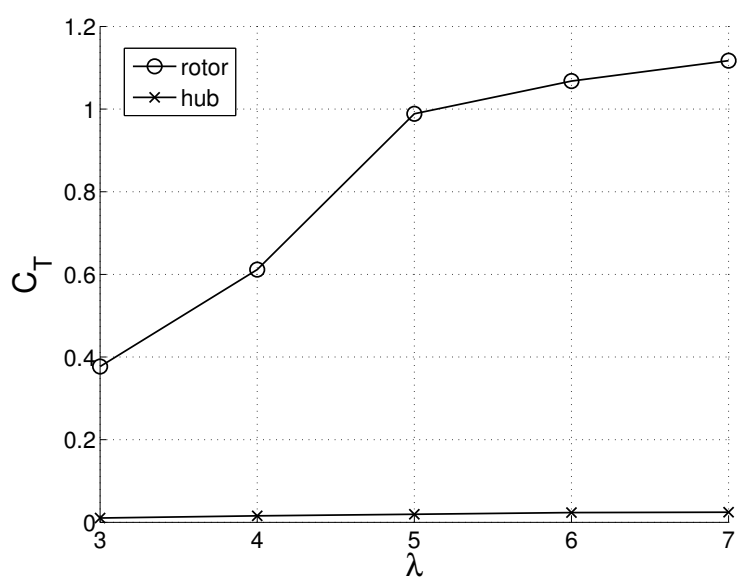

Figure 10: Thrust components of the bare turbine at various $\lambda$.

investigated. The thrust on the rotor also increases with increasing $\lambda$ and reaches a thrust coefficient of $C_{T}=0.98$ at the design point.

\subsection{Performance of the bare turbine}

The performance of the devices is examined by multiple measures of performance:

- power: measured by the power coefficient, $C_{P}$

The first of the performance measures is the power coefficient introduced in section 2 It is important to note that the power coefficient for all of the results are defined in terms of the total frontal (blocked) area of the device (and not simply the disc area) as the reference area. When later comparing devices (i.e. bare, ducted, and opencentre turbines) using a constant blockage ratio and constant inflow, the denominators of equations (2) and (3) are the same for all devices. Comparison of the power coefficient is thus a direct comparison of the actual power extracted by devices of the same outer diameter.

- power density : measured by the power density coefficient, $C_{P D}$

Power density is measured using an alternative definition of the power coefficient,

$$
C_{P D}=\frac{P}{\frac{1}{2} \rho A_{\text {rotor }} U_{\infty}^{3}} .
$$

In this alternative definition, the reference area employed is the turbine (rotor) swept area. For a bare turbine with no hub both reference areas are the same, therefore $C_{P D}$ and $C_{P}$ are equal. For the ducted or open-centre turbine, however, the reference area may differ substantially depending on the device design, thus leading to significant differences in power and power density.

- efficiency: measured by the basin efficiency, $\eta_{\text {basin }}$ 
The third measure of performance employed is the basin efficiency, $\eta_{\text {basin }}$. Analysing the performance of a tidal turbine simply through the power coefficient fails to portray the full picture. The wake behind the turbine mixes with the bypass flow, this introduces further, unavoidable energy removal from the flow. Mixing losses are especially important when comparing bare and ducted devices. The presence of a duct within the flow exerts an additional thrust on the fluid. This added thrust leads to significantly more energy being extracted from the flow than is converted into useful energy. As tidal flows are finite resources, the total energy removed from the flow represents an important feature of each device. Thus a device efficiency definition is introduced, which relates the useful power generated to the total power removed from the flow, defined as the basin efficiency,

$$
\eta_{\text {basin }}=\frac{\text { useful power }}{\text { total power removed from flow }}
$$

The total power removed from the flow can be calculated using the thrust on both the turbine disc and the structure if applicable (such as a duct). As shown in equation (13), the power removed from the flow can be calculated by multiplying the total thrust in streamwise direction by the upstream velocity in streamwise direction:

$$
\eta_{\text {basin }}=\frac{P}{\left(T_{\text {turbine }}+T_{\text {structure }}\right)_{\xi} U_{\infty}}
$$

The thrust and velocity directional component are those of the direction of the free-stream, $\xi$, in the case of axial flow this is the $x$-direction.

For the bare turbine simulated with RANS-BEM all three measures of performance reach their peak at the design point, $\lambda=5$, see figure 11. The power coefficient increases steeply until it reaches a value of $C_{P, \max }=0.6$, after which it reduces moderately for higher $\lambda$. The inclusion of the hub means that the power and power density differ very slightly, however the difference is marginal, with $C_{P D, \max }=0.62$. Note that the Betz limit of 0.59 is exceeded due to non-negligible blockage of the finite simulation domain. For the basin efficiency the rise and drop off is comparatively flat and almost symmetrically centred around the maximum of $\eta_{\text {basin }}=0.6$. For low $\lambda$, the moderate increase of $\eta_{\text {basin }}$ is due to the power increasing more steeply than the thrust. For $\lambda>\lambda_{\text {design }}$, power decreases slightly, while the thrust of the device increases further, thus leading to a decrease in basin efficiency.

\section{Analysis of the ducted turbine}

The ducted turbine is analysed in using the same metrics as described in the previous section. Various operating points are examined through a variation of tip-speed ratio, mimicking changes in rotational velocity for a given inflow velocity. 

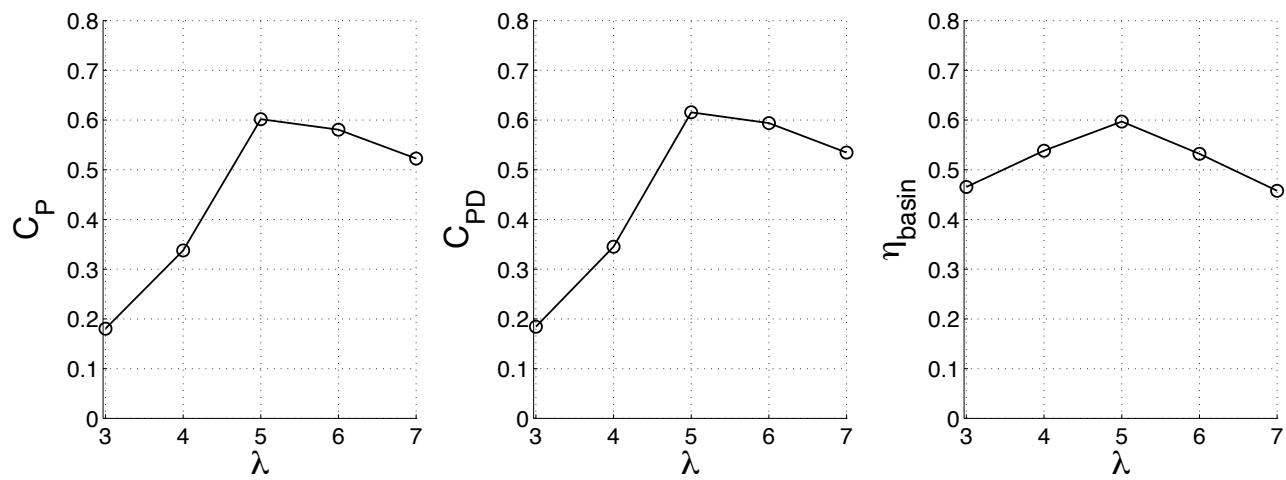

Figure 11: Performance of the bare turbine at various $\lambda$.

\subsection{Flow field for the ducted turbine}

Figure 12 presents the flow field results for the ducted turbine in axial flow for $2 \leq \lambda \leq 6$. For comparison the contour levels are the same as in Fig 8

The general flow features on the duct show the same features as observed for the actuator disc simulations, see Belloni et al. (2013). For low $\lambda$, and therefore low flow resistance within the duct, the flow stays attached to the duct exterior (nozzle-contoured flow) and a significant velocity increase is visible within the duct, with the highest velocity reached in the region of the rotor plane. At higher $\lambda$, separation occurs on the exterior duct surface as described in Belloni et al. (2013). Though not pictured here, the separation bubble starts to form at $\lambda=3$ and is fully developed at $\lambda=4$. No separation is observed on the duct interior surface.

As the resistance within the duct is increased, the flow velocity is reduced approaching the duct, before accelerating within the duct. At $\lambda=4$ (design point) these effects balance, so that the flow velocity at the rotor is approximately equal to the free-stream velocity. At higher $\lambda$ values, the rotor within the ducted turbine applies less thrust to the flow (see figure 14 in following section) such that the axial flow velocity at the rotor plane increases slightly again. The swirl velocity is also reduced, following a reduction in torque. A radial variation in velocity through the rotor can be observed, most pronounced at $\lambda=6$.

Azimuthally averaged flow data is presented in figure 13 for five values of $\lambda$, with the design point, $\lambda=4$, presented in black. As seen in figure 12 the increase in velocity inside the duct is substantial for tip-speed ratios below the design point. At the design point the axial velocity at the rotor is fairly constant at $u_{x} / U_{\infty} \approx 1$, with slight increases for higher $\lambda$. This variation in axial velocity, combined with the decreased / increased rotational velocities compared to the design point, leads to a substantial increase in $\alpha$ for low $\lambda$ and a moderate drop in $\alpha$ for high $\lambda$. While these changes in axial velocity and angle of attack lead to low local thrust coefficients across the whole blade span for low tip-speed ratios, the result for high tip-speed ratios is more varied. Though the increase in $\alpha$ across the span is marginal, the local thrust coefficient increases significantly across the blade span to the tips. This can partially be 

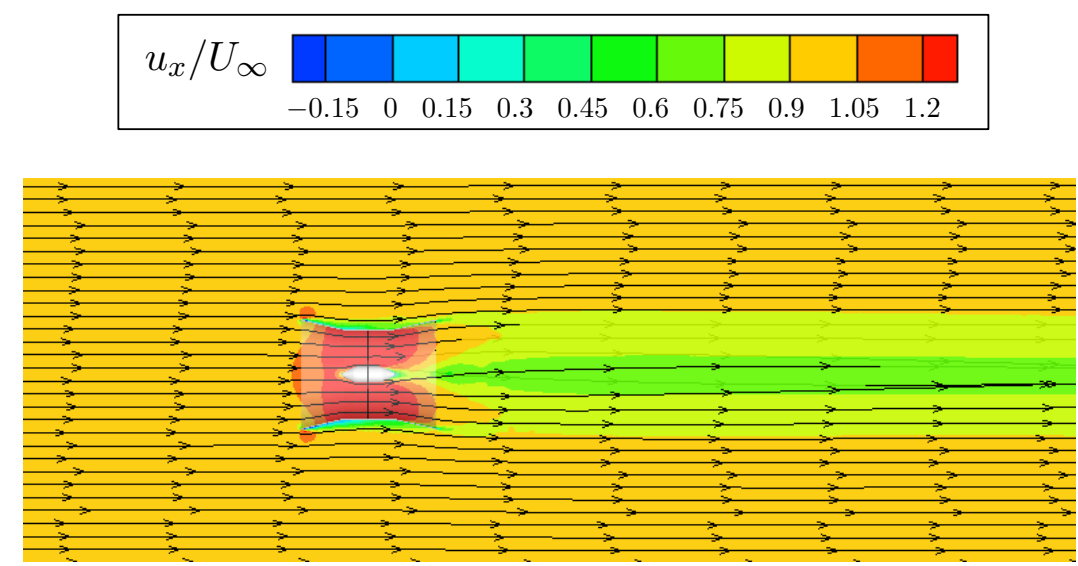

(a) $\lambda=2$

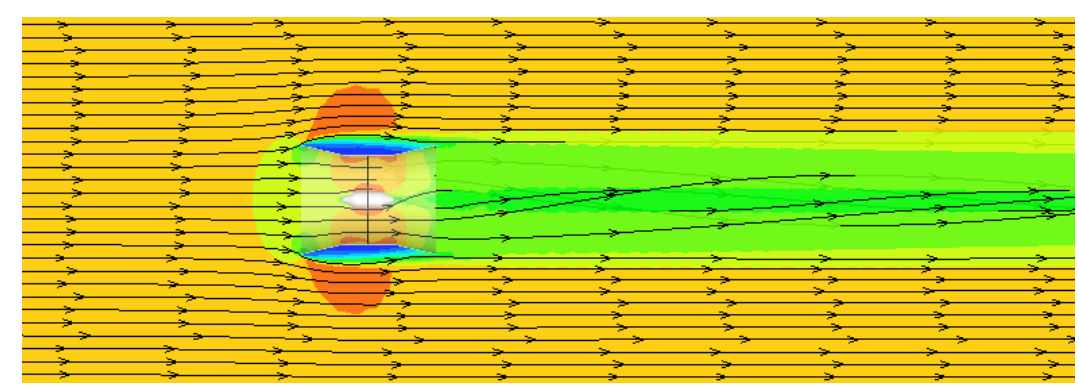

(b) $\lambda=4$, design point

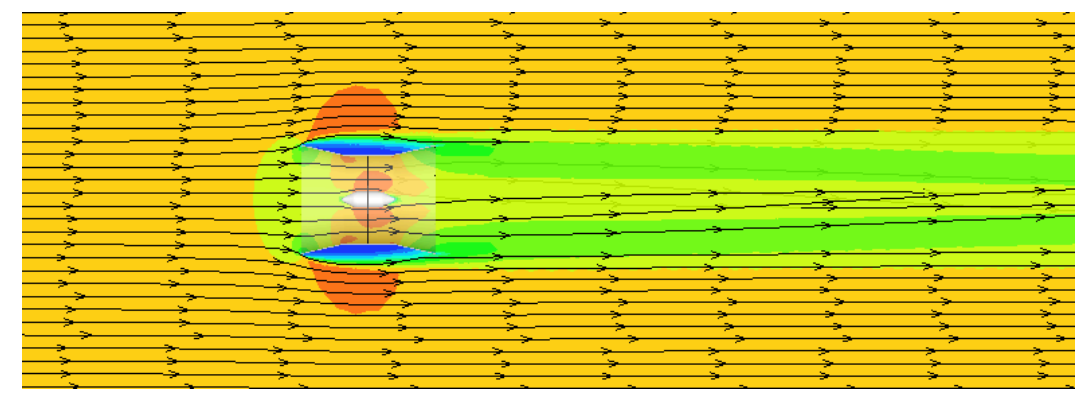

(c) $\lambda=6$

Figure 12: Flow field of the ducted turbine for various levels of $\lambda$.

attributed to

- the increase in blade incident velocity, $U_{\text {rel }}$, which affects the blade thrust quadratically

- the variation in $\alpha$, leading to a variation in $C_{l}$ and hence to a variation in axial blade force

- the slight drop in axial velocity towards the tip region, which affects the normalisation quadratically. 

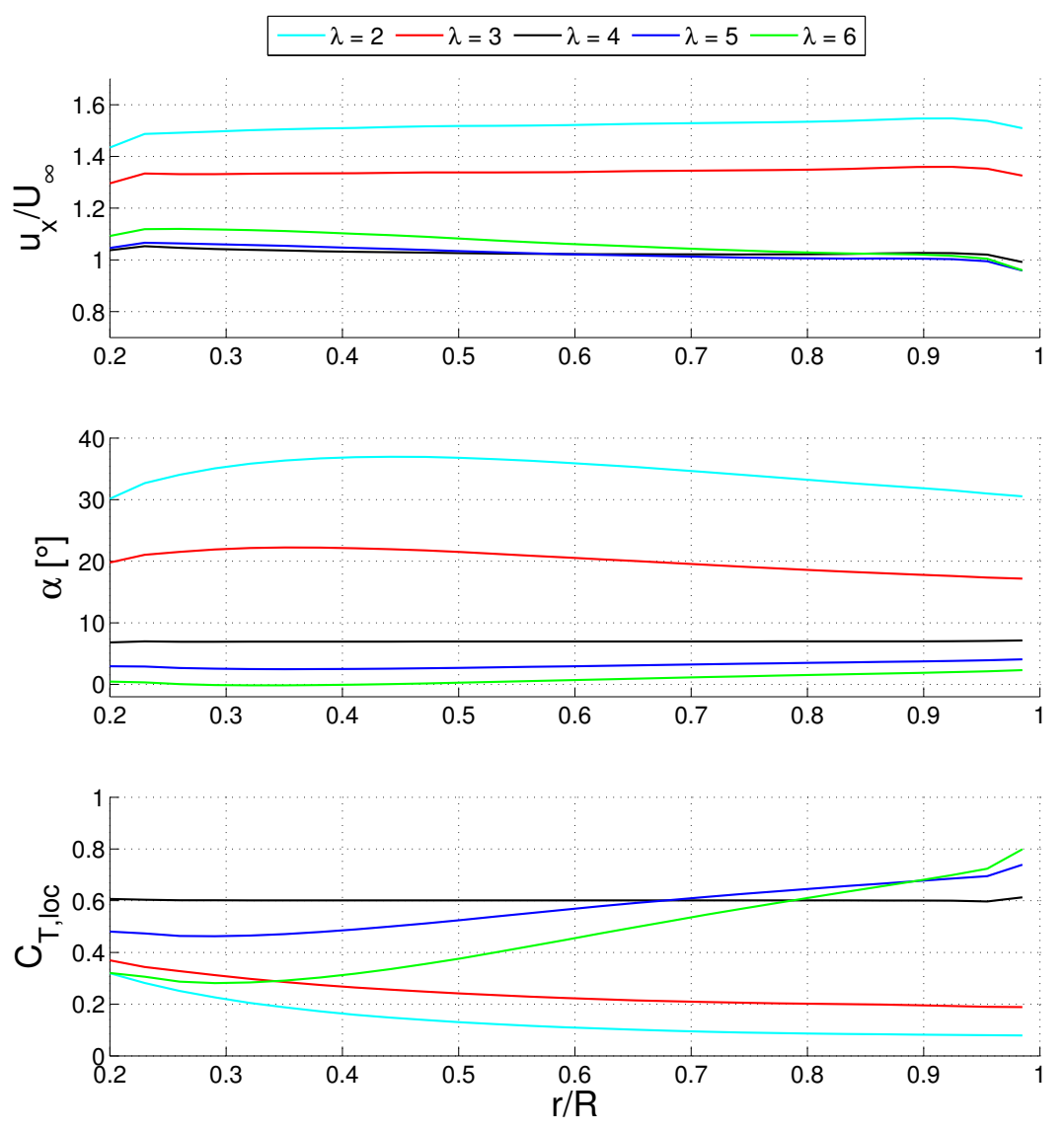

Figure 13: Azimuthally averaged flow results of the ducted turbine at $2 \leq \lambda \leq 6$.

\subsection{Thrust on the ducted turbine}

The axial thrust on the ducted turbine is obtained in the same way as for the bare turbine, with the thrust on the duct being obtained in the same manner as for the hub. Figure 14 presents the results for a range of $\lambda$ with the thrust split into three components; rotor, duct and hub.

The qualitative results compare well to those obtained in Belloni et al. (2013). As for the actuator disc analysis, rotor and duct thrust are of a similar magnitude. The thrust on the duct reaches its maximum when the flow on the outer duct surface is fully separated, at $\lambda=4$. The thrust on the hub is small in comparison and reaches a maximum at the design point. The total thrust of the device at the design point is $C_{T, \text { tot, duct }}=0.79$ and thus lower than that of the bare turbine at the design point $\left(C_{T, \text { tot, bare }}=0.98\right)$. The rotor thrust does not increase past the design point, but actually decreases slightly for higher tip-speed ratios, a feature that can also be observed in the results of a ducted turbine presented by McIntosh et al. (2011). 


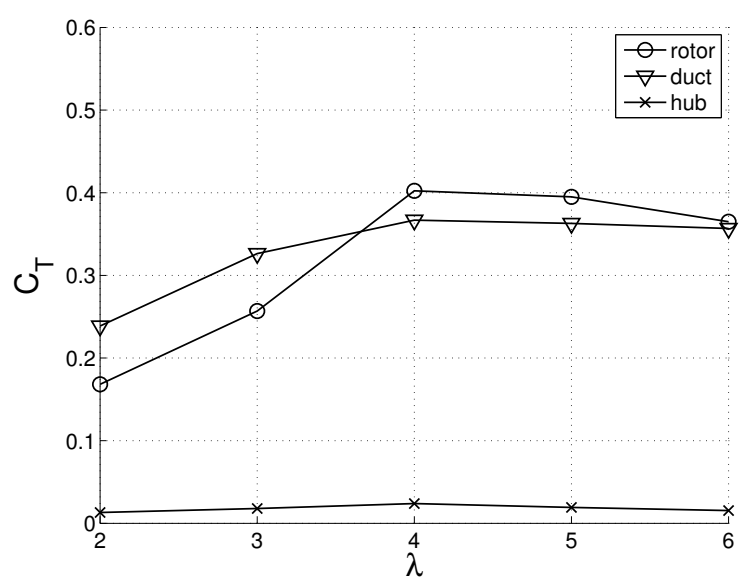

Figure 14: Thrust components of the ducted turbine at various $\lambda$.

It appears that the ducted rotor is unable to exert additional resistance to the flow; increasing the tip-speed-ratio further beyond the design point leads to the flow being spilt about the outside of the duct, hence limiting the maximum thrust and power that can be exerted and generated by the ducted turbine.

\subsection{Performance of the ducted turbine}

The performance of the ducted turbine is presented together with that of the bare turbine in figure 15 . The overall performance peak, applicable to all measures of performance, is reached at the design point of $\lambda=4$. The maximum power coefficient and power density coefficient are $C_{P, \max }=0.39$ and $C_{P D \text {, max }}=0.59$ respectively. For the basin efficiency the peak occurs at the design point, with a value of $\eta_{\text {basin, } \max }=0.48$.
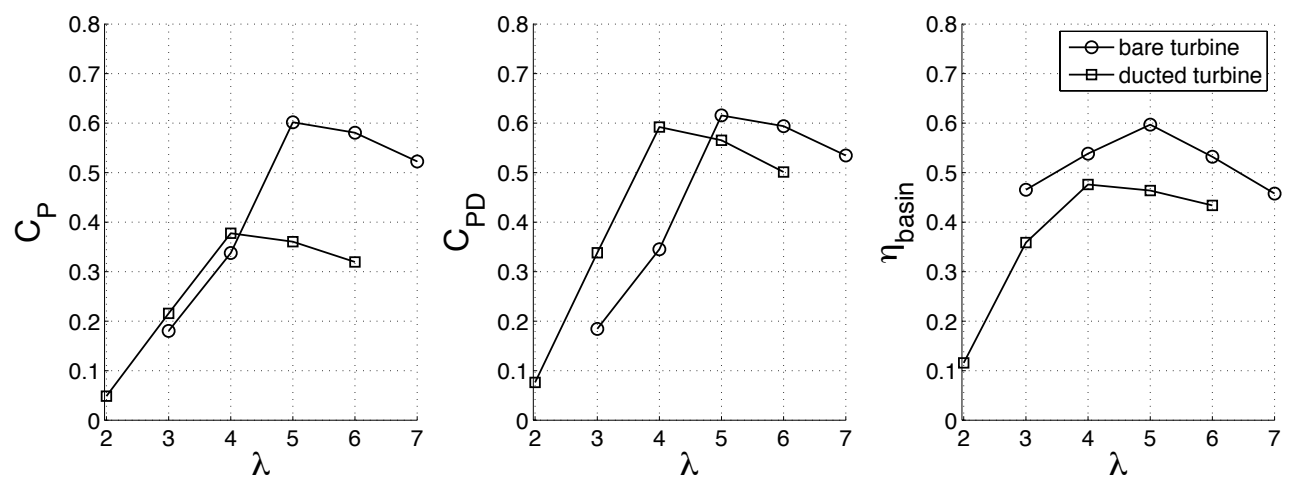

Figure 15: Performance of the ducted turbine.

Compared to the bare turbine, $\eta_{\text {basin, max }}$ is reduced by $15 \%$. For $\lambda<\lambda_{\text {design }}$, the significant duct drag leads to further reductions in efficiencies compared to the bare turbine. For $\lambda>\lambda_{\text {design }}$ the ducted rotor unloads, leading to a reduced power extraction from the flow, and therefore a result in $\eta_{\text {basin }}$ closer to that of the bare turbine. Note that while peak 
power density is similar for the two turbines, the bare turbine achieves a substantially higher power coefficient.

\section{Analysis of the open-centre turbine}

The same analysis method is now applied to the open-centre turbine. As presented in section 4 a single aperture size is studied and a ring shaped hub is included in this analysis.

\subsection{Flow field of the open-centre turbine}

The flow field of the open-centre turbine is presented in figure 16 For all but the lowest $\lambda$ investigated, a small separation bubble forms at the outer surface of the duct near the leading edge. For $\lambda=5$ some separation is visible on the duct interior near the diffuser exit.

A ring-shaped hub has been placed around the aperture in order to simulate a blade support at the root, as has been suggested by the industry (see O'Rourke et al. (2010)). Although the hub ring introduces further flow features on its inner and outer surfaces, the general flow feature of the aperture - flow jetting - is clearly visible at all levels of $\lambda$. In general, it seems that the jetting flow accelerates the wake mixing process, due to the additional mixing layer present at the interior of the wake, thus leading to faster wake recovery than for the ducted turbine.

Both the flow velocity at the rotor plane and the swirl in the wake vary with $\lambda$ much in the same way as the ducted turbine. A significant velocity increase is visible through the rotor plane at low tip-speed ratios. As the tip-speed ratio increases towards the design point, $\lambda=3$, this effect is balanced by the flow expansion close to the duct inlet. For $\lambda>3$ thrust exerted by the rotor drops, as previously observed in figure 12 and thus the velocity at the rotor plane again increases. Maximum swirl is observed at the design point, where maximum torque is achieved.

The azimuthally averaged rotor data for the open-centre turbine (figure 17 ) follows the same trends discussed for the ducted turbine, presented in figure 13 . As for the ducted turbine, strong radial variations in $C_{T, \text { loc }}$ are observed, and more moderate radial variations of $\alpha$ and $u_{x}$. For $\lambda<3, \alpha$ is very high, leading to stalled operation.

\subsection{Thrust on the open-centre turbine}

The results of the analysis of the forces in the flow direction are presented in figure 18 As before, the force components are split into rotor, duct and hub ring. The reduced loading on the duct compared to the ducted turbine (see figure 14 ) is immediately apparent. This can be attributed to the more streamlined exterior duct shape, resulting in only a small separation on the leading edge outer surface. The thrust variation on the rotor is comparable to that of the ducted turbine, with a steep increase for low $\lambda$ until the design point and then a slight reduction for higher $\lambda$. In a similar 

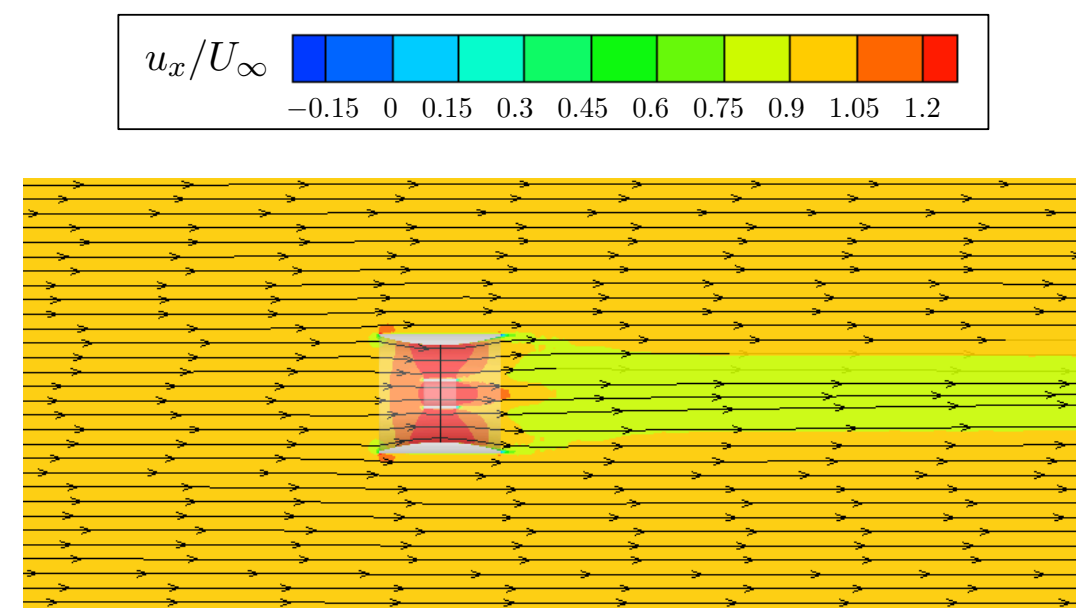

(a) $\lambda=1$

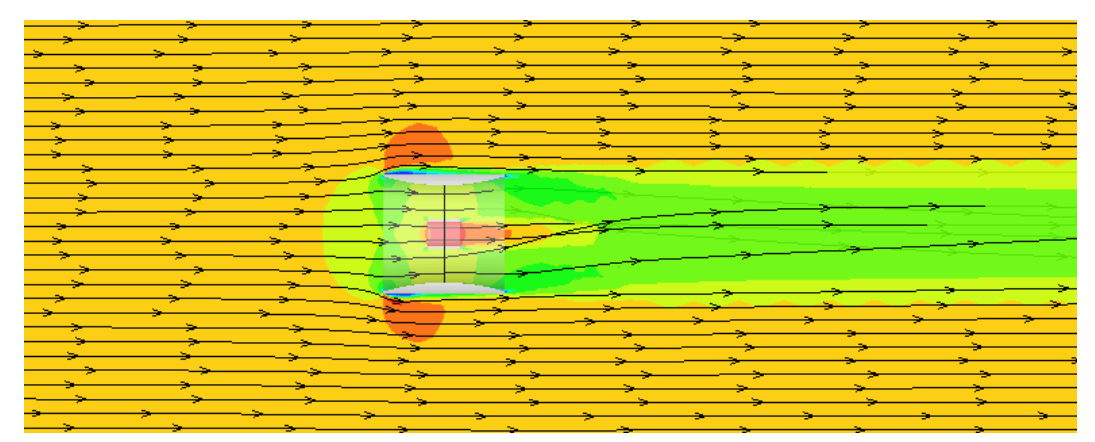

(b) $\lambda=3$, design point

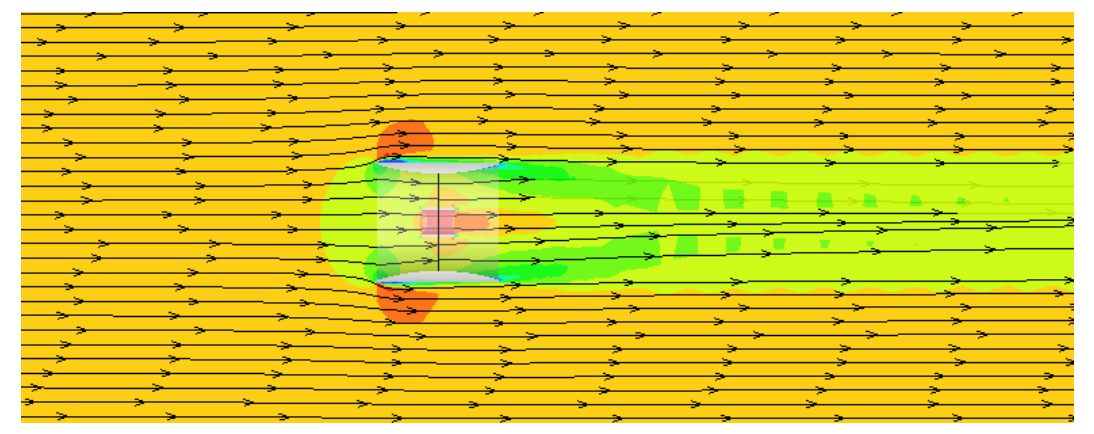

(c) $\lambda=5$

Figure 16: Flow field of the open-centre turbine for three levels of $\lambda$.

manner to the other devices, the thrust on the hub ring is an order of magnitude smaller than that of rotor and duct.

Minimal variation with $\lambda$ is observed for $C_{T \text {, hub ring }}$, as the hub ring presents only a small frontal area. The total thrust of the device at design point is $C_{T, \text { tot }}=0.63$, significantly lower than for both bare and ducted turbines. To summarise, figure 19 presents the total thrust on each of the turbine devices over the full range of tip speed ratios. 

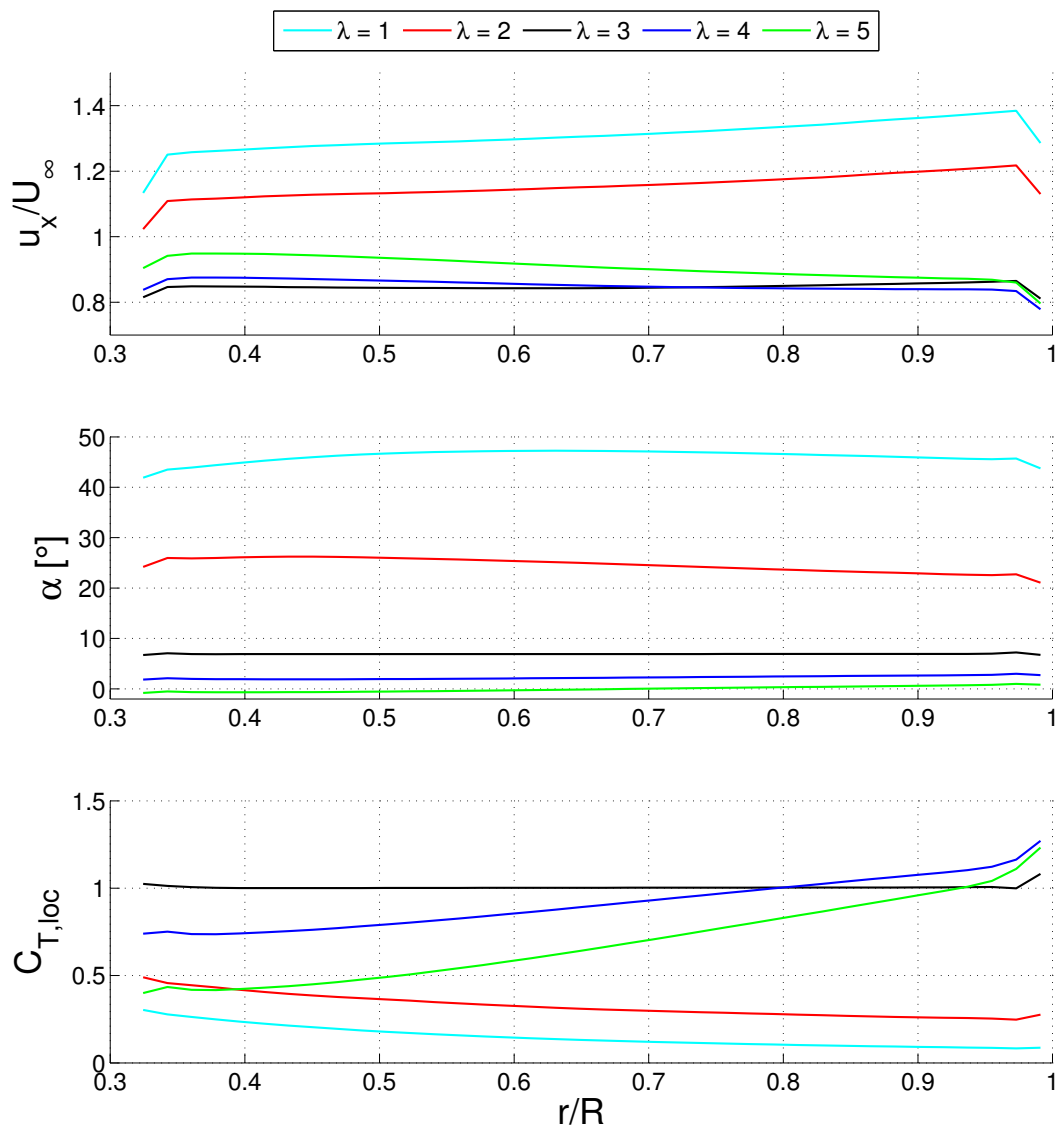

Figure 17: Azimuthally averaged flow results of the open-centre turbine at various $\lambda$.

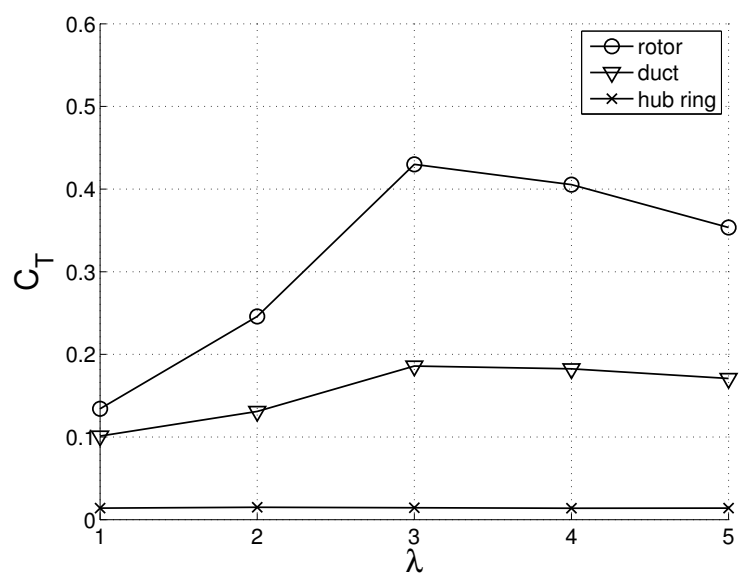

Figure 18: Thrust components of the open-centre turbine at various $\lambda$. 


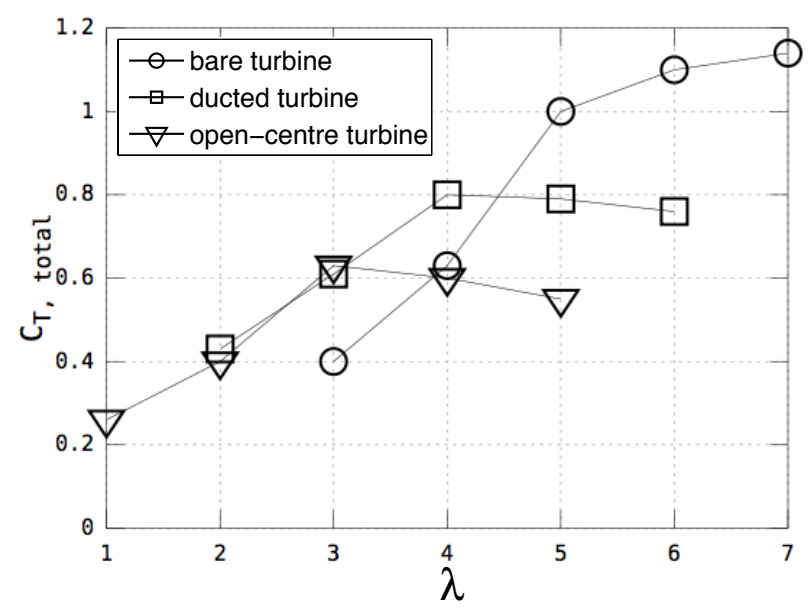

Figure 19: Total thrust of each turbine device at various $\lambda$.

\subsection{Performance of the open-centre turbine}

The three measures of performance for the open-centre turbine are also presented in figure 20 . All of the maximum performance values in figure 20 lie roughly $10-15 \%$ below those of the open-centre turbine actuator disc simulations detailed in Belloni (2013). While the performance coefficients follow the same trend as the ducted turbine, the maximum performance values differ. The open-centre turbine reaches lower values of $C_{P, \max }$ and $C_{P D \text {, max }}$, while reaching a higher value of $\eta_{\text {basin, max }}=0.53$. The latter is a direct result of the lower thrust levels reported in figure 18 , leading to lower parasitic power extraction compared to the ducted turbine. From this it can be concluded that the streamlined duct shape used for the open-centre turbine is better able to convert axial thrust to power.
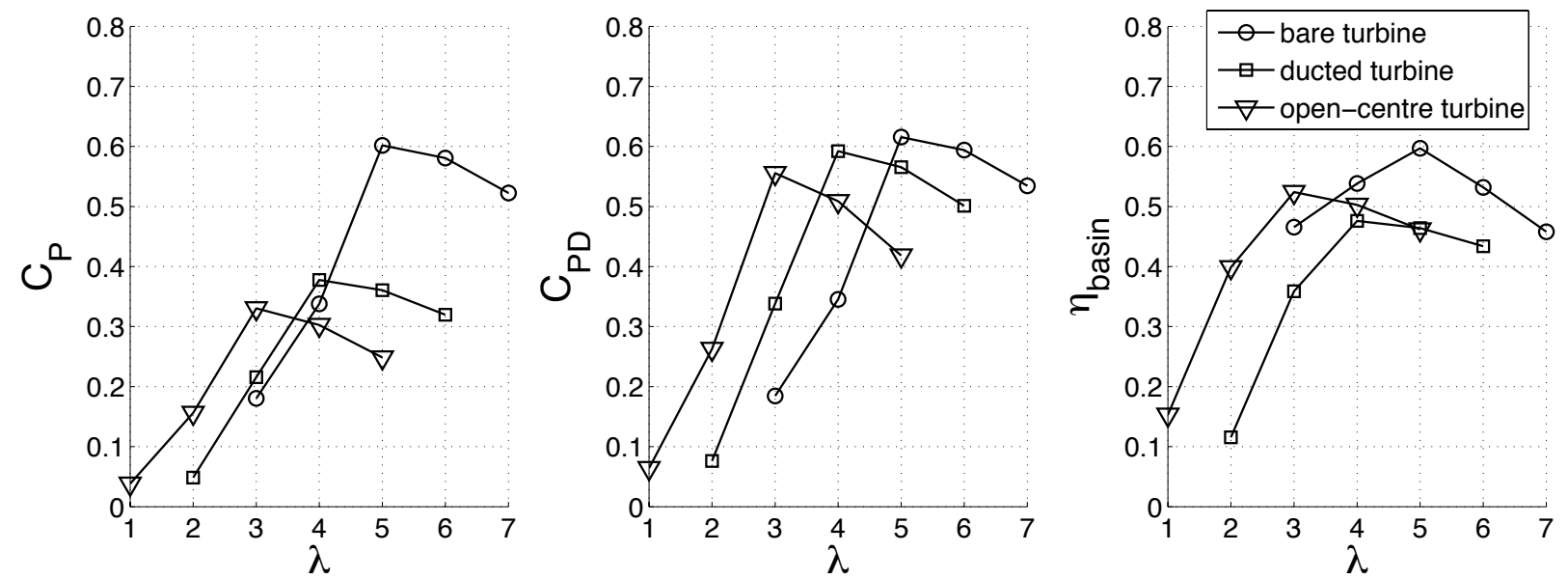

Figure 20: Performance of the open-centre turbine analysed with RANS-BEM at various $\lambda$, compared to the bare and ducted turbines. 


\section{Conclusions}

A RANS-implemented BEM code has been presented and applied to bare, ducted, and open-centre turbines. Rotor designs for the three devices have been generated using a RANS-BEM-integrated rotor design tool following a constant local thrust design approach. The design iterations were conducted for a range of tip-speed ratios and thrust settings and the designs with highest yielding power were chosen. The designs for the three devices include hub structures modelled approximately on existing devices proposed by the industry. The purpose has been to provide as fair as possible comparison of the three generic device types.

The chosen rotor designs were applied to their respective devices and simulated in axial inflow for various tip-speed ratios. In general, the performance trends measured at the design point follow those of the actuator disc simulations presented in Belloni et al. (2013) and Belloni (2013). However, there are distinct differences in the flow field, the forces on the devices as well as off-design operation.

In all RANS-BEM simulations the circumferential force exerted by the turbine on the flow is clearly visible in the swirling motion of the wake. Together with the inclusion of the hub, they form the two main differences to the actuator disc flow field, giving a much more realistic representation of a turbine wake.

For all three devices analysed, the thrust exerted by the hub structures are small compared to the rotor thrust and thus only have a small impact on the turbine performance. The duct results in almost $50 \%$ of the total axial thrust loading for the ducted turbine and slightly less for the more streamlined duct of the open-centre turbine studied.

Both ducted and open-centre devices exhibit a limit to the thrust on the rotor and the induction factor close to the design point. At tip-speed ratios higher than the design point, the rotors placed within a duct impart less axial and circumferential thrust on the flow, leading to an increasing velocity at the disc plane.

For axial flow, the performance of the devices modelled employing RANS-BEM lies roughly $8-15 \%$ lower than for the actuator disc simulations reported elsewhere (Belloni and Willden, 2011), when comparing the devices at their respective design points. This reduction in performance is mostly due to the blade drag captured by the RANS-BEM model, which is not modelled by the actuator disc. The bare turbine sees a lower performance penalty compared to the actuator disc simulations than the other two devices, which may be attributed to tip-effects modelled in RANS-BEM which were not applied to the rotors operating in a duct. The bare turbine significantly outperforms the ducted and open-centre turbines in terms of $C_{P}$ and moderately in terms of $\eta_{\text {basin }}$, while all three devices perform similarly in terms of $C_{P D}$. The open-centre turbine exhibits a lower $C_{P}$ than the ducted turbine while exhibiting a higher $\eta_{\text {basin }}$.

Putting the non-dimensional coefficients into perspective, representative numbers may be calculated for the three devices operating at their respective peak operating points. At a typical rated flow speed of $2.5 \mathrm{~m} / \mathrm{s}$ the bare turbine produces $0.97 \mathrm{MW}$ and the ducted and open-centre turbines $0.61 \mathrm{MW}$ and $0.53 \mathrm{MW}$ respectively. The thrust loading on the three devices at these operating points are $0.64 \mathrm{MN}$ for the bare, $0.52 \mathrm{MN}$ for the ducted, and $0.41 \mathrm{MN}$ for the 
open-centre turbine.

The results presented in this study have been achieved for two particular bidirectional duct geometries. The geometries chosen are based on designs proposed by the industry and were therefore deemed representative for this analysis. Due to the low number of duct shapes analysed, however, the question of general applicability of the results arises. A parametric study of interior and exterior bidirectional duct shapes was conducted by Fleming and Willden (2016), who analysed eight duct shapes including a straight pipe, providing evidence that the axial flow trends presented here also hold for a broad range of bidirectional duct shapes.

The present study compares the devices on their hydrodynamic performance in axial flow. While exhibiting inferior hydrodynamic performance in axial flow, bidirectional ducts may provide other benefits in practical application. For instance, the ducts can shield the rotor from extreme flow variations or debris present in the flow. Further, when exposed to moderately yawed flow, as often present in tidal flows, bidirectional ducts efficiently realign the flow such that the rotor is exposed to axial flow and can work efficiently (Belloni et al., 2013).

\section{Acknowledgements}

The authors thank the Engineering and Physical Sciences Research Council, the German Academic Exchange Service (DAAD), the Oxford Martin School, and the Bracken Fund for funding this work. They thank Peter Stansby and Thomas Adcock for their constructive reviews of the work presented here.

\section{References}

Ahmed, M. R., 2012. Blade sections for wind turbine and tidal current turbine applications - current status and future challenges. International Journal on Energy Research 36. ANSYS Inc., 2009. ANSYS FLUENT 12.0 Theory Guide.

Aplsey, D. D., Leschzinger, M. A., 1999. Advanced turbulence modelling of separated flow in a diffuser. Flow, Turbulence and Combustion 63, 81-112.

Batten, W. M. J., Harrison, M., Bahaj, A. S., 2013. The accuracy of the actuator disc-RANS approach for predicting the performance and far wake of a horizontal axis tidal stream turbine. Philosophical Transactions of the Royal Society A 371.

Belloni, C. S. K., 2013. Hydrodynamics of ducted and open-centre tidal turbines. DPhil thesis, University of Oxford.

Belloni, C. S. K., Willden, R. H. J., 2011. Flow field and performance analysis of bidirectional and open-centre ducted tidal turbines. In: Proc. $9^{\text {th }}$ European Wave and Tidal Energy Conference, Southampton.

Belloni, C. S. K., Willden, R. H. J., Houlsby, G. T., 2013. A numerical analysis of bidirectional ducted tidal turbines in yawed flow. Marine Technology Society Journal 47 (4), 23-35.

Clean Current Power Systems Inc., 2013. Clean current tidal turbines. http://www.cleancurrent.com/tidal-turbines accessed April 4, 2013.

Evans, R., McAdam, R., Royle, M., McEwen, L., 2013. Optimum geometry for axial flow free stream tidal turbine blades. In: Proc. 10 ${ }^{\text {th }}$ European Wave and Tidal Energy Conference, Aalborg. 
Fleming, C. F., Willden, R. H. J., 2016. Analysis of bi-directional ducted tidal turbine performance. International Journal of Marine Energy 16, $162-173$.

Foreman, K. M., Gilbert, B. L., Oman, R. A., 1978. Further investigations of diffuser augmented wind turbines. Solar Energy $20,305-311$.

Fuglsang, P., Dahl, K. S., Antoniou, I., 1999. Wind tunnel tests of the Ris $\varnothing-A 1-18$, Ris $\emptyset-A 1-21$ and Ris $\varnothing-A 1-24$ airfoils. Tech. Rep. R-1112(EN), Risø.

Gaden, D. L. F., Bibeau, E. L., 2010. A numerical investigation into the effect of diffusers on the performance of hydro kinetic turbines using a validated momentum source turbine model. Renewable Energy 35.

Hansen, M. O. L., Sørensen, N. N., Flay, R. G. J., 2000. Effect of placing a diffuser around a wind turbine. Wind Energy 3.

Hunter, W., Nishino, T., Willden, R. H. J., 2015. Investigation of tidal turbine array tuning using 3d reynolds-averaged navier?stokes simulations. International Journal of Marine Energy 10, 39-51.

Lilley, G. M., Rainbird, W. J., 1956. A preliminary report on the design and performance of ducted windmills. Tech. Rep. 102, College of Aeronautics, Cranfield University.

MacLeod, A., Barnes, S., Rados, K., Bryden, I., 2002. Wake effects in tidal current turbine farms. In: Proc. International Conference on Marine Renewable Energy.

Malki, R., Williams, A. J., Croft, T. N., Togneri, M., Masters, I., 2013. A coupled blade element momentum - computational fluid dynamics model for evaluating tidal stream turbine performance. Applied Mathematical Modelling 37 (5), 3006 - 3020.

Masters, I., Malki, R., Williams, A. J., Croft, T. N., 2013. The influence of flow acceleration on tidal stream turbine wake dynamics: A numerical study using a coupled BEM-CFD model. Applied Mathematical Modeling 38.

McIntosh, S. C., Fleming, C. F., Willden, R. H. J., 2011. Embedded RANS-BEM tidal turbine design. In: Proc. $9^{\text {th }}$ European Wave and Tidal Energy Conference, Southampton.

Menter, F. R., 1993. Zonal two-equation k- $\omega$ turbulence model for aerodynamic flows. AIAA Paper (1993-2906).

Mikkelsen, R., 2003. Actuator disc methods applied to wind turbines. PhD thesis, Technical University of Denmark.

O’Rourke, F., Boyle, F., Reynolds, A., 2010. Tidal energy update 2009. Applied Energy 87 (2), 398 - 409.

Phillips, D. G., Richards, P. J., Flay, R. G. J., 2005. Diffuser development for a diffuser augmented wind turbine using computational fluid dynamics. Technical Report. University of Auckland.

Sale, D., Jonkman, J., Musial, W., 2009. Hydrodynamic optimization method and design code for stall-regulated hydrokinetic turbine rotors. In: Proc. $28^{\text {th }}$ International Conference on Ocean, Offshore, and Arctic Engineering.

Schluntz, J., 2014. Numerical methods for tidal turbine array modelling. DPhil thesis, University of Oxford.

Schluntz, J., Willden, R. H. J., 2015. The effect of blockage on tidal turbine rotor design and performance. Renewable Energy 81, 432-441.

Setoguchi, T., Shiomi, N., Kaneko, K., 2004. Development of two-way diffuser for fluid energy conversion system. Renewable Energy 29.

Sørensen, J. N., Myken, A., 1992. Unsteady actuator disc model for horizontal axis wind turbines. Journal of Wind Engineering and Industrial Aerodynamics 39, 139-149.

Thorpe, T., 2005. The advantages of ducted over unducted turbines. In: Proc. $6^{\text {th }}$ European Wave and Tidal Energy Conference.

Turnock, S. R., Phillips, A., Banks, J., Nicholls-Lee, R., 2011. Modelling tidal current turbine wakes using a coupled RANS-BEMT approach as a tool for analysing power capture of arrays of turbines. Ocean Engineering 38.

van Bussel, G. J. W., 2007. The science of making more torque from wind: Diffuser experiments and theory revisited. Journal of Physics: Conference Series 75.

van Drentham Susman, H. F. A., Stewart, K. R., Stewart, D., 05 2011. Power generator and turbine unit. Patent. 